\title{
Analysis of Urban Effects in Oklahoma City using a Dense Surface Observing Network*
}

\author{
Xiao-Ming Hu, Ming Xue, and Petra M. Klein \\ Center for Analysis and Prediction of Storms, and School of Meteorology, University of Oklahoma, \\ Norman, Oklahoma \\ BRADLEY G. ILLSTON \\ Oklahoma Mesonet, Oklahoma Climatological Survey, University of Oklahoma, Norman, Oklahoma
}

\section{SHENG CHEN}

Key Laboratory of Beibu Gulf Environmental Evolution and Resources Utilization, Guangxi Teachers Education University, Ministry of Education, Nanning, Guangxi, China, and Hydrometeorology and Remote Sensing Laboratory, and School of Civil Engineering and Environmental Science, University of Oklahoma, Norman, Oklahoma

(Manuscript received 26 July 2015, in final form 14 October 2015)

\begin{abstract}
Many studies have investigated urban heat island (UHI) intensity for cities around the world, which is normally quantified as the temperature difference between urban location(s) and rural location(s). A few open questions still remain regarding the UHI, such as the spatial distribution of UHI intensity, temporal (including diurnal and seasonal) variation of UHI intensity, and the UHI formation mechanism. A dense network of atmospheric monitoring sites, known as the Oklahoma City (OKC) Micronet (OKCNET), was deployed in 2008 across the OKC metropolitan area. This study analyzes data from OKCNET in 2009 and 2010 to investigate OKC UHI at a subcity spatial scale for the first time. The UHI intensity exhibited large spatial variations over OKC. During both daytime and nighttime, the strongest UHI intensity is mostly confined around the central business district where land surface roughness is the highest in the OKC metropolitan area. These results do not support the roughness warming theory to explain the air temperature UHI in OKC. The UHI intensity of OKC increased prominently around the early evening transition (EET) and stayed at a fairly constant level throughout the night. The physical processes during the EET play a critical role in determining the nocturnal UHI intensity. The near-surface rural temperature inversion strength was a good indicator for nocturnal UHI intensity. As a consequence of the relatively weak near-surface rural inversion, the strongest nocturnal UHI in OKC was less likely to occur in summer. Other meteorological factors (e.g., wind speed and cloud) can affect the stability/depth of the nighttime boundary layer and can thus modulate nocturnal UHI intensity.
\end{abstract}

\section{Introduction}

Because of the different properties of the urban surface, temperatures over urban areas are typically higher than over the surrounding rural areas, a phenomenon

\footnotetext{
* Supplemental information related to this paper is available at the Journals Online website: http://dx.doi.org/10.1175/JAMC-D15-0206.s1.

Corresponding author address: Dr. Xiao-Ming $\mathrm{Hu}$, Center for Analysis and Prediction of Storms, University of Oklahoma, 120 David L. Boren Blvd., Norman, OK 73072.

E-mail: xhu@ou.edu
}

well known as the urban heat island (UHI; Oke 1976, 1981, 1982; Arnfield 2003). During the past few decades, many studies have been conducted to observe and document UHI magnitude/intensity in cities around the world. UHI intensity is often quantified as the difference in temperature of near-surface air or land surface between urban site(s) and surrounding rural site(s). Most of these previous studies were limited to discussing paired urban-rural differences, either between one urban and one rural site or between urban mean and rural mean temperature (e.g., Gedzelman et al. 2003; Wienert and Kuttler 2005; Yow and Carbone 2006; Alonso et al. 2007; Basara et al. 2008; Miao et al. 
2009; Steeneveld et al. 2011; Husain et al. 2014; Hu and Xue 2016).

Relative to its temporal characteristics, the spatial characteristics of UHI intensity (UHII) are much less investigated, largely due to difficulties and costs of deploying multiple instruments with enough density across the urban area (Basara et al. 2010; Chapman et al. 2015). Because the in situ weather stations in urban areas are usually sparse (Kim and Baik 2005; Stone 2007; Tan et al. 2010; Basara et al. 2011; Muller et al. 2013; Fenner et al. 2014), UHII at the spatial scale of a city is sometimes derived from remotely sensed land surface temperatures (Voogt and Oke 2003; Fung et al. 2009; Nichol et al. 2009; Zhou and Shepherd 2010; Peng et al. 2012; Winguth and Kelp 2013). However, there are inherent issues associated with remotely sensed UHII. Satellite-derived land surface temperature only account for the radiant temperatures of surfaces seen by the radiometer, and the data correspond to averages across the area of a pixel (Roth et al. 1989). As a consequence, roofs, treetops, and open horizontal areas are oversampled and vertical surfaces and areas below tree crowns are neglected in remotely sensed UHII. The physical properties, and radiative and turbulent environments of facets that are well represented by remote sensing data, often differ from those that are undersampled (Arnfield 2003). Thus, the remote sensing poorly samples the true surface temperature within the city. As a result, remotely sensed land surface temperature UHII and in situ measured air temperature UHII can have very distinctly different behaviors, such as different diurnal variation (Cui and de Foy 2012). While air temperature UHII is reported to be stronger at night than in the day in many studies (Arnfield 2003; Souch and Grimmond 2006), remotely sensed land surface UHI shows stronger intensity during daytime than during nighttime (Roth et al. 1989; Imhoff et al. 2010; Schwarz et al. 2011; Jin 2012; Klok et al. 2012; Peng et al. 2012; Zhao et al. 2014). Thus, further investigation of spatial and temporal characteristics of UHII using consistent, quality observations of air temperature is required to improve the understanding of the impacts of urbanization (Bottyán and Unger 2003; Grimmond 2006; Huang et al. 2008; Basara et al. 2010; Grimmond et al. 2010; Chen et al. 2012; Muller et al. 2013; Schatz and Kucharik 2014; Dou et al. 2015). The information regarding spatial distribution of air temperature UHI of a city can also help provide heat information at a neighborhood scale for use in future detailed public health analyses and heat hazard mitigation strategies (Heusinkveld et al. 2014; Chapman et al. 2015; Debbage and Shepherd 2015).

Several studies have shown that UHII is dictated by the intrinsic characteristics of a city (Oke 1981, 1982;
Unger 2004; Grimmond 2007; Hart and Sailor 2009; Georgakis et al. 2010; Ryu and Baik 2012; Adachi et al. 2014; Barlow 2014) and modulated by external meteorological factors (Morris and Simmonds 2000; Hu et al. 2013b). Oke et al. (1991) used a simple energy balance model to assess the relative importance of the commonly stated intrinsic causes of UHI under calm and cloudless conditions, including anthropogenic heat, thermal properties/moisture availability of the materials of the city, street canyon geometry, and urban greenhouse gases. The first three of these were identified as the main intrinsic causative factors contributing to the UHII in a modeling study conducted by Ryu and Baik (2012). A quantitative attribution of various contributions to UHII is estimated in Zhao et al. (2014) using a surface energy balance analysis. Low efficiency at dissipating heat from urban surfaces due to larger aerodynamic resistance is diagnosed to be the dominant contributor to daytime UHII in cities in the humid southeast and south-central United States (including Oklahoma), which coincides roughly with the KoppenGeiger temperate climate zone. Improved understanding of causative factors contributing to the UHII is still needed for UHI mitigation management (Hidalgo et al. 2010; Loughner et al. 2012; Clinton and Gong 2013; Li et al. 2013; Theeuwes et al. 2013; Li et al. 2014; Zhao et al. 2014).

Conflicting results have been reported for the seasonal variation of UHII (Arnfield 2003; Yang et al. 2013). Using the air temperature-defined UHI, some previous studies (e.g., Magee et al. 1999; Steinecke 1999; Montávez et al. 2000; Jonsson 2004; Kim and Baik 2005; Hinkel and Nelson 2007; Zhou and Shepherd 2010; Memon et al. 2011; Yang et al. 2013) reported that UHIs are the weakest in summer and strongest in winter, while other studies found that UHIs are best developed in summer or warm half of the year (Karl et al. 1988; Schmidlin 1989; Klysik and Fortuniak 1999; Philandras et al. 1999; Morris et al. 2001; Fortuniak et al. 2006; Camilloni and Barrucand 2012; Fenner et al. 2014; Schatz and Kucharik 2014; van Hove et al. 2015). Most studies based on analysis of satellite-derived land surface temperature reported that UHII over many cities was significantly higher in summer than in winter, for example, Imhoff et al. (2010) and Peng et al. (2012) for cities of the United States, K. C. Wang et al. (2007) and Zhang et al. (2005) for Beijing, Li et al. (2012) for Shanghai, Meng and Liu (2013) for Jinan, and Zhang et al. (2010) for other cities. Factors governing the seasonal variation of UHII need further investigation.

Oklahoma City (OKC), Oklahoma $\left(35.468762^{\circ} \mathrm{N}\right.$, $97.516304^{\circ} \mathrm{W}$ ), spans $\sim 1610 \mathrm{~km}^{2}$. It is one of the 10 largest cities by land area in the United States. The 


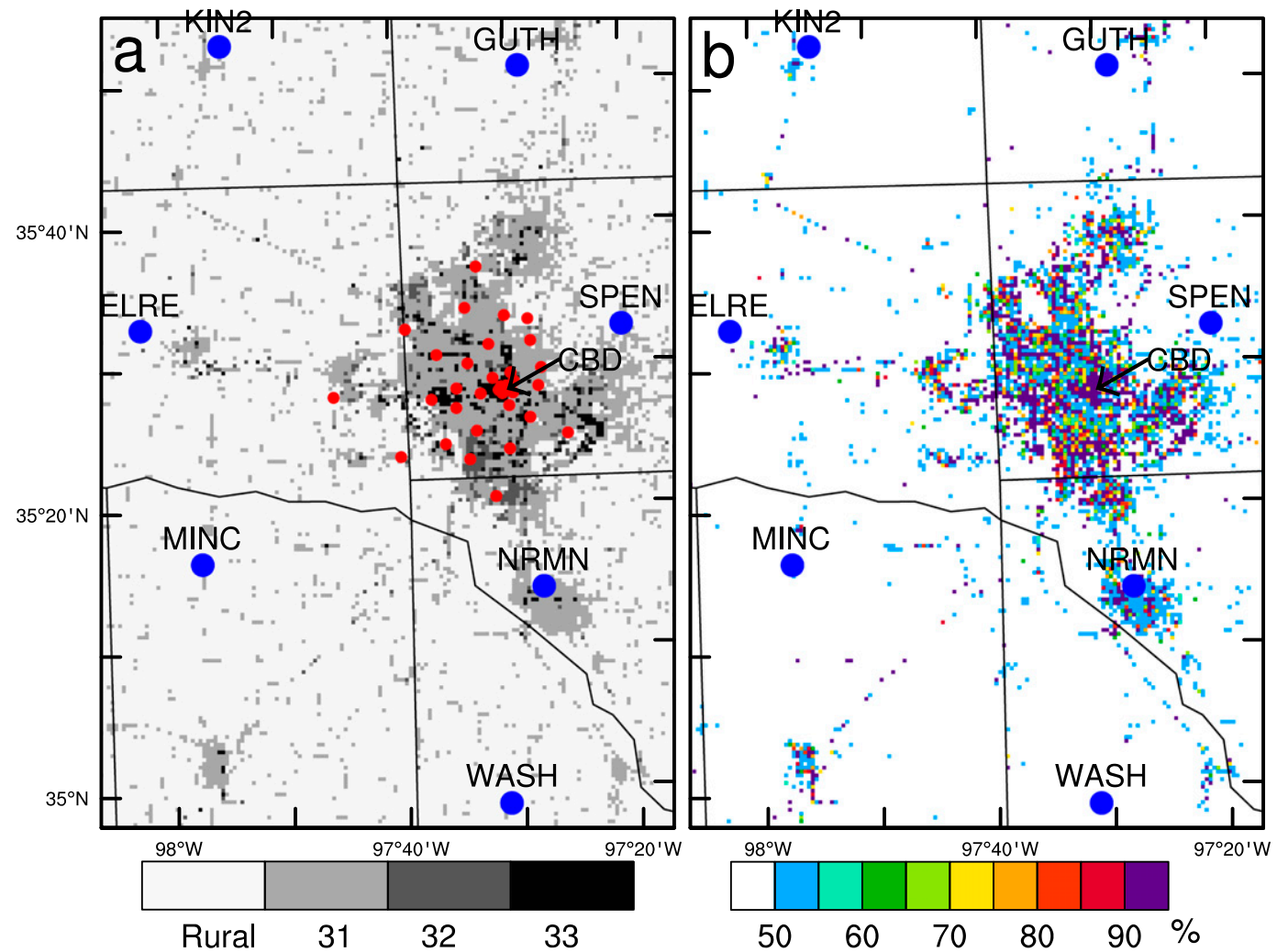

FIG. 1. (a) Location of the OKCNET stations (red dots) and seven surrounding Oklahoma Mesonet sites (i.e., ELRE, GUTH, KIN2, MINC, NRMN, WASH, and SPEN in blue dots). The CBD of OKC is also marked. The background shade corresponds to the land-use categories derived from the USGS 2006 NLCD at a spatial resolution of $30 \mathrm{~m}$, in which the urban land use was divided into three categories: low-intensity residential (category 31), high-intensity residential (category 32), and commercial/industrial (category 33). In the CBD, symbols overlap due to the high spatial density of the OKCNET stations. (b) Spatial distribution of built-up area fraction also derived from the NLCD.

terrain of $\mathrm{OKC}$ is quite flat. The temporal variation of UHII in OKC has been investigated in observational studies (Basara et al. 2008; Basara et al. 2010; Klein 2012) for a few short-term periods (mostly for July 2003). Studies with research and weather prediction models further focused on evaluating the skill of these models in predicting UHII with urban canopy layer parameterization schemes of different levels of complexity (Liu et al. 2006; Lemonsu et al. 2009; Hu et al. 2013b; Husain et al. 2013). During 2007 and 2008, a dense network of atmospheric monitoring sites [i.e., the OKC Micronet (OKCNET)] was deployed across the OKC metropolitan area (Basara et al. 2011), which provided data for long-term monitoring of UHII in OKC at the spatial scale of the city. Thus, given the dense meteorological observations across the OKC metropolitan area, the objectives of this study are to 1) illustrate the spatial pattern of UHII in the OKC metropolitan area, 2) investigate the diurnal and seasonal variations of UHII in OKC, and 3) diagnose how UHI formation is related to land surface and boundary layer processes. Since previous studies have shown that UHII is closely related to wind speed (Fast et al. 2005; Hu et al. 2013b), some of its spatiotemporal characteristics are also discussed.

\section{Data and methods}

Our analysis focuses on the OKC metropolitan area (Fig. 1). Embedded within the OKC urbanized area is a well-defined central business district (CBD) that spans $\sim 20 \mathrm{~km}^{2}$, with the average building height being around $50-70 \mathrm{~m}$ and the tallest building being $152 \mathrm{~m}$ high (during the years studied). This study utilized surface meteorological data collected at the stations around the OKC metropolitan area from two networks, that is, the OKCNET and the Oklahoma Mesonet (site locations in Fig. 1; Brock et al. 1995; McPherson et al. 2007).

The OKCNET is an operational network designed to improve atmospheric monitoring across the OKC metropolitan area, which was officially commissioned in 
November 2008 (Basara et al. 2011). OKCNET consists of a total of 39 stations with an average spacing of approximately $3 \mathrm{~km}$, including 36 stations mounted on traffic signals at a height of $\sim 9 \mathrm{~m}$ above ground level (AGL) and 3 stations in OKC (i.e., OKCN, OKCW, and OKCE) deployed following the protocols of the Oklahoma Mesonet. Basara et al. (2010, 2011) provided detailed information about the siting of the OKCNET sites and their classification using different criteria proposed in the literature. Basara et al. (2010) used a simplified classification for a composite analysis of UHI in OKC for a heat wave episode, in which OKCNET sites are grouped into three categories (i.e., urban, suburban, and rural) based on the surrounding land cover characteristics. A more detailed climate-based classification of urban sites, that is, seven urban climate zones (UCZs), was proposed by Oke (2004). The urban OKCNET stations fall into UCZ classifications UCZ1 and UCZ2 (intensely developed urban), the suburban OKCNET stations fall into UCZ classifications UCZ4-UCZ7 (highly developed, medium, or low-density urban, suburban to semirural), and the rural OKCNET stations fall into UCZ classification UCZ7 (semirural; Basara et al. 2010; Basara et al. 2011).

The Oklahoma Mesonet is a rural network of 120 meteorological stations with minimal influences from urban landscapes (McPherson et al. 2007; Basara et al. 2008). Each of the Oklahoma Mesonet stations is located within a fenced $100 \mathrm{~m}^{2}$ plot of land and measures more than 20 environmental variables, including wind at 2 and $10 \mathrm{~m}$, air temperature at 1.5 and $9 \mathrm{~m} \mathrm{AGL}$, and shortwave radiation, that are used in the analysis of this study. The average temperature at $9 \mathrm{~m} \mathrm{AGL}$ at the seven Oklahoma Mesonet sites surrounding the OKC metropolitan area [i.e., El Reno (ELRE), Guthrie (GUTH), Kingfisher (KIN2), Minco (MINC), Norman (NRMN), Washington (WASH), and Spencer (SPEN); see Fig. 1] are calculated as background rural temperature following the approach of Basara et al. (2008) and Klein (2012). The UHI intensity at each OKCNET site is defined as the difference between the temperature at the OKCNET site and the background rural temperature. Note that the average elevation difference between the OKCNET sites ( $\approx 370 \mathrm{~m}$ above sea level) and the seven rural Oklahoma Mesonet sites ( $\approx 363 \mathrm{~m}$ above sea level) is approximately $7 \mathrm{~m}$. Using mean temperature at the seven Oklahoma Mesonet sites as background rural temperature provides a more robust measure of UHI intensity and minimizes the inherent variability between rural sites that can impact the magnitude of UHI values (Hawkins et al. 2004; Sakakibara and Owa 2005; Hunt et al. 2007; Lee and Baik 2010; Mohsin and Gough 2012). For example, as a result of the urbanization in recent years, the NRMN station was at the edge of an urban area according to the U.S. Geological Survey (USGS) 2006 National Land Cover Data (NLCD; Fig. 1), where the measured rural temperature may be biased high. On the other hand, the ELRE site to the west of the metropolitan area is known to experience more rapid nighttime cooling than other nearby Oklahoma Mesonet sites and often has a low bias (Hunt et al. 2007).

Richardson number Ri, an indicator of dynamic stability of an air layer, considers the effects of both wind shear and buoyancy on the atmospheric stability. To investigate the diurnal cycle of near-surface atmospheric stability and its impact on UHI development, the Ri at Oklahoma Mesonet sites around OKC was estimated using (Bodine et al. 2009)

$$
\mathrm{Ri}=\frac{g\left[\left(T_{9 \mathrm{~m}}-T_{1.5 \mathrm{~m}}\right) / \Delta z_{T}+\Gamma_{d}\right] \Delta z_{u}^{2}}{T_{1.5 \mathrm{~m}}\left(u_{10 \mathrm{~m}}-u_{2 \mathrm{~m}}\right)^{2}},
$$

where $g$ is the acceleration due to gravity, $\Gamma_{d}=0.01^{\circ} \mathrm{Cm}^{-1}$ is the dry adiabatic lapse rate, $T_{9 \mathrm{~m}}$ and $T_{1.5 \mathrm{~m}}$ are the air temperatures measured at 9 and $1.5 \mathrm{~m} \mathrm{AGL}$, and $u_{2 \mathrm{~m}}$ and $u_{10 \mathrm{~m}}$ are the wind speed at 2 and $10 \mathrm{~m}$ AGL, respectively. The height differences between the measurement levels are $\Delta z_{T}=7.5 \mathrm{~m}$ for air temperature and $\Delta z_{u}=8.0 \mathrm{~m}$ for wind speed.

One of the surrounding Oklahoma Mesonet sites, KIN2, was deployed in March 2009. A few OKCNET sites were decommissioned in November 2010, that is, reliable temperature data over the urban area were no longer available from thereon. Thus, the investigation of urban effects focuses on the period of April 2009-October 2010 in this study. Precipitation has been reported to reduce the difference in the heating/cooling rate between the urban and rural areas, thus suppressing UHI development (Chow and Roth 2006; Lee and Baik 2010). Time periods with precipitation at any OKCNET sites or the seven surrounding Oklahoma Mesonet sites were not considered in this study to avoid the impact of precipitation on UHII. Since the spatial distribution of UHII is to be examined, all the sites need to have the same measurement period; so only the time periods when data from all the sites were available between April 2009 and October 2010 (total $6937 \mathrm{~h}$ ) were considered when investigating urban-rural differences. On the other hand, the Oklahoma Mesonet has been continuously operational. The temperature inversion between 1.5 and $9 \mathrm{~m} \mathrm{AGL}$ at the seven Oklahoma Mesonet sites surrounding OKC were examined for a longer period (i.e., April 2009-December 2012) to diagnose possible seasonal variations of UHI intensity.

In addition to values at spatially distributed observation sites, spatial patterns of UHII and wind speed were analyzed using the kriging interpolation method. The kriging method is popular in mapping meteorological and 

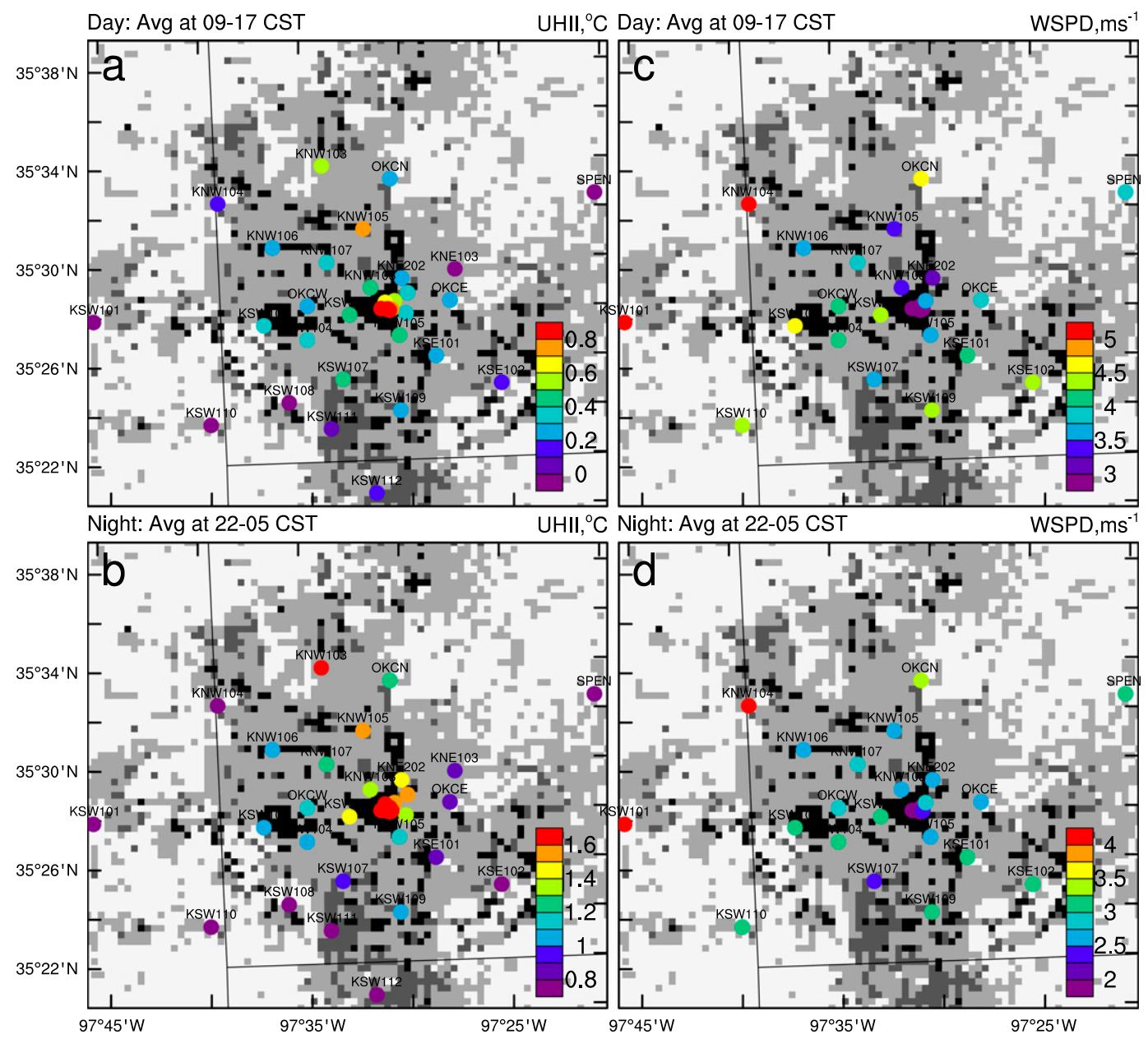

FIG. 2. Spatial distribution of (a),(b) mean UHII (defined as the difference between temperature at each OKCNET site and rural background temperature computed as average temperature at the seven Oklahoma Mesonet sites) and (c),(d) wind speed during (top) daytime (i.e., 0900-1700 CST) and (bottom) nighttime (i.e., 2200-0500 CST) in April 2009-October 2010. The background shade shows again the land-use categories derived from the 2006 NLCD. In the CBD, not all station names are shown.

chemical variables based on station observation data in diverse applications (e.g., Chen et al. 2014; Smoliak et al. 2015; Zou et al. 2015). The kriging function embedded in the Interactive Data Language (IDL, version 8.4) was used in this study as in Chen et al. (2014).

\section{Results}

\section{a. Mean spatial distributions and diurnal variations of UHI and wind speed}

\section{1) UHI INTENSITY AND RELATIONSHIP WITH SPATIAL DISTRIBUTIONS OF WIND SPEED}

The spatial distributions of UHII and wind speed are overlaid on top of land-use categories in Fig. 2. The strongest UHI intensity was mostly confined around the CBD during both daytime and nighttime except for a hotspot of OKCNET site KNW103 during nighttime (Fig. 2b). The spatial maps of UHI intensity produced by the kriging method illustrate elongated heat plumes north of the CBD during both daytime and nighttime (Figs. 3a,b), which can be explained by downwind transport of heat by the predominant southerly winds.

While urban effects on temperature are quite widely discussed in the literature, less information is available about urban effects on wind patterns (Klein 2012; Klein and Galvez 2014). Spatial patterns of mean wind speed around OKC were examined using the OKCNET observations (Figs. 2c,d). The corresponding analyses based on the kriging method are also shown in Figs. 3c and 3d. Unlike the elongated feature of UHI intensity, 

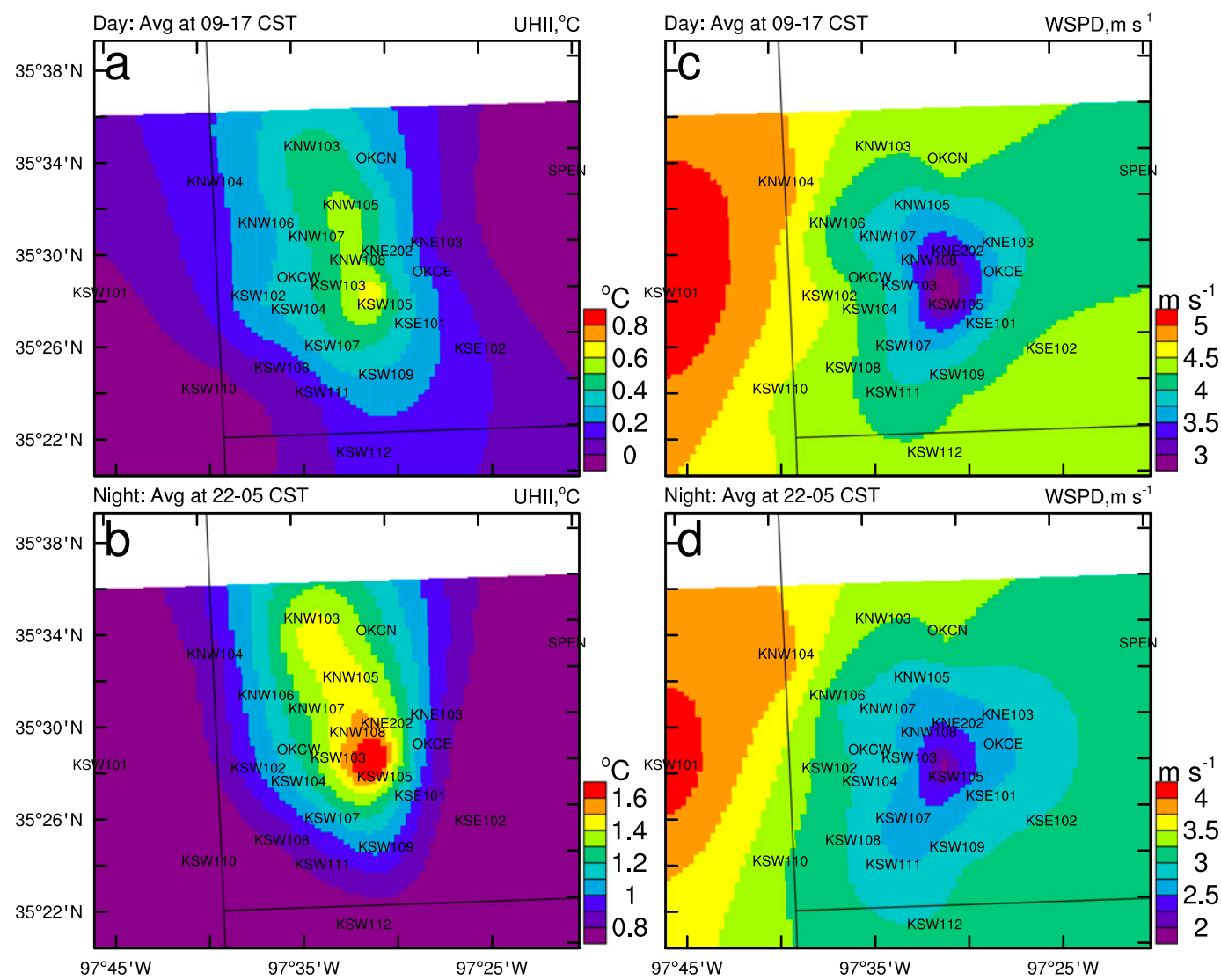

FIG. 3. Spatial patterns of (a),(b) mean UHII and (c),(d) wind speed computed with a kriging interpolation method (using the data shown in Fig. 2) during (top) daytime and (bottom) nighttime in April 2009-October 2010. As reference, the location of some of the sites is indicated by the station name.

wind speeds showed a more concentric pattern around the CBD. Wind speed was slowest during both daytime and nighttime around the CBD, where the UHI intensity was the strongest. Having the largest wind speed reduction centered around the CBD suggests a strong impact of surface roughness that is largest in this area. Roughness also affects the aerodynamic resistance of sensible heat transfer. Larger (smaller) roughness leads to stronger (weaker) vertical mixing and more (less) efficiency to transfer sensible heat from the land surface to the atmospheric boundary layer (ABL) (Lee et al. 2011).

In the humid southeast and south-central United States (including Oklahoma), the rural land is densely vegetated, owing to ample precipitation, and is aerodynamically rough. Zhao et al. (2014) argue that in this humid region, sensible heat transfer from the surface to the $\mathrm{ABL}$ is more efficient in rural than in urban areas, leading to relatively lower (higher) surface temperatures in the rural (urban) area. Such a process is attributed in Zhao et al. (2014) to largely explain MODISderived daytime land surface UHII in this region, which is termed as the roughness warming theory. The roughness warming theory was derived when comparing the aerodynamic resistance/roughness between rural land-use categories and a single urban category (i.e., the intraurban variation of roughness is ignored). Given the intraurban variation of roughness due to different building densities and heights, according to the roughness warming theory, aerodynamically smoother urban areas should experience stronger daytime UHII than aerodynamically rougher urban areas (e.g., CBD), assuming that the ratio of roughness length of momentum to heat remains roughly constant across the entire urban area (Moriwaki and Kanda 2006; Kato et al. 2008; Sugawara and Narita 2009; De Ridder et al. 2012). However, this is not the case for OKC. On the contrary, the aerodynamically roughest CBD area experienced the highest UHII (Figs. 2a, b, 3a,b). Thus, the roughness warming theory of Zhao et al. (2014) used for explaining the land surface UHI may not explain the air temperature UHI observed in this study. Other intrinsic causative factors, for example, thermal properties of urban surfaces (Grimmond and Oke 1999; Ogoli 2003; Liu et al. 2006; Zhu et al. 2009; Bohnenstengel et al. 2011; 

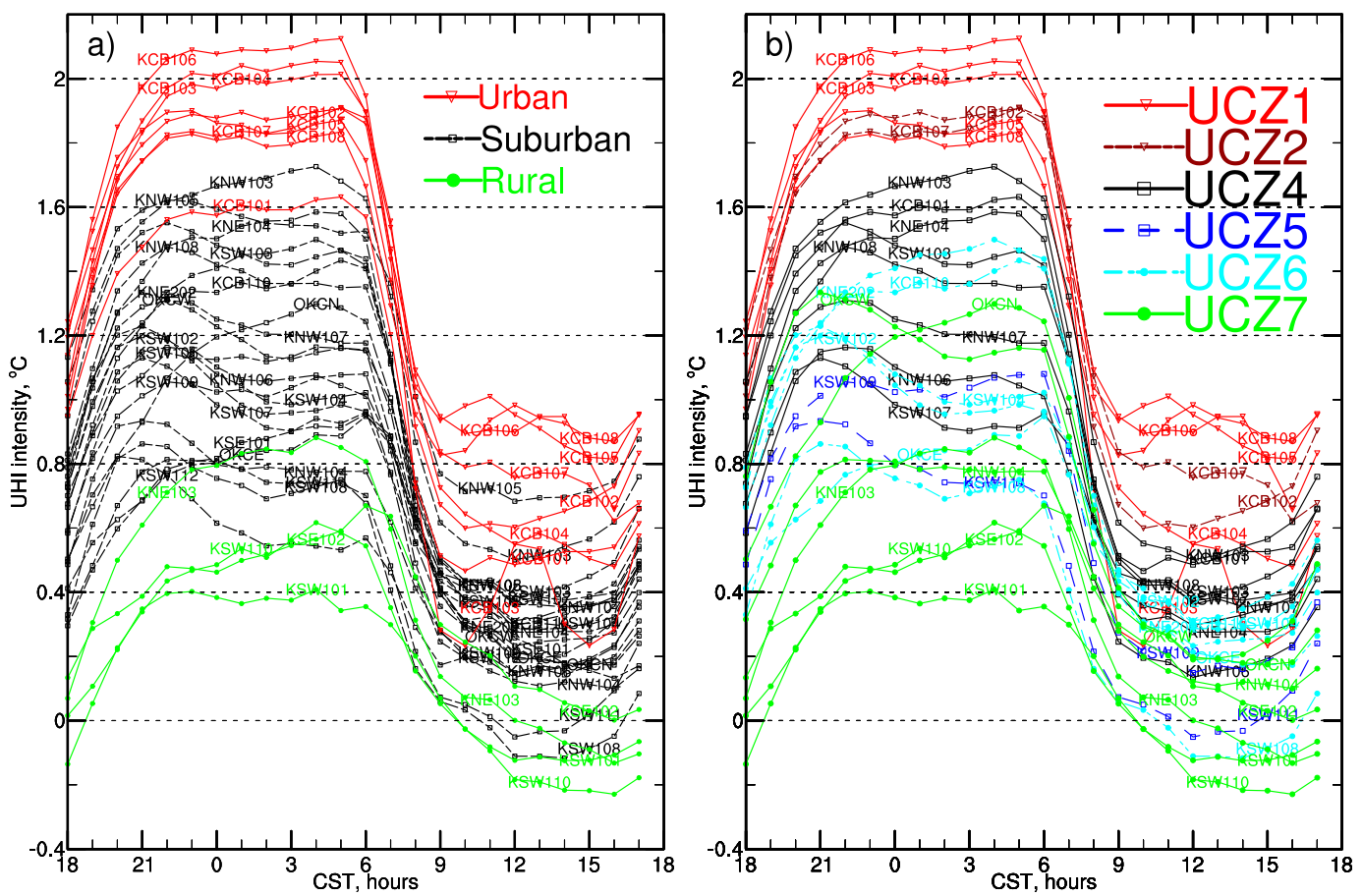

FIG. 4. (a) Mean diurnal variation of UHII at each OKCNET site during April 2009-October 2010. The OKCNET sites are classified into three categories (i.e., urban, suburban, and rural) with different colors based on the neighborhood land cover characteristics surveyed in Basara et al. (2010). (b) As in (a), but the OKCNET sites are classified into different UCZs defined by Oke (2004).

Yang et al. 2013), anthropogenic heat (Ichinose et al. 1999; Fan and Sailor 2005; Grossman-Clarke et al. 2005; Schlünzen et al. 2010), reduction in evaporative cooling due to impervious surfaces (Taha 1997), and trapping of longwave radiation by urban buildings (Arnfield 2003) must have played more important roles in contributing to the air temperature UHII in OKC, as suggested in a modeling study conducted by Ryu and Baik (2012).

Detailed diurnal variation of UHI is still subject to debate (Memon et al. 2009; Imhoff et al. 2010; Hu et al. 2013b; Zhao et al. 2014). A better understanding of UHIIs' temporal variation could help to diagnose its causative factors ( $\mathrm{Hu}$ et al. 2013b). Mean diurnal variation of UHII between April 2009 and October 2010 at OKCNET sites was calculated after removing the periods when precipitation occurred or data from certain sites were missing. All the sites show a prominent diurnal variation of UHII with higher values during nighttime (Figs. 4a,b). The UHII normally increased rapidly around the early evening transition (EET), that is, 1900-2000 central standard time (CST), and then stayed at a roughly constant level throughout the night until early the next morning when the convective boundary layer developed. Note that since the sunset and sunrise time varies, the transition time in the diurnal variation of UHII is different in different seasons. Such an issue will be discussed in section $3 \mathrm{~b}$. The characteristics of diurnal variation of UHII shown in Fig. 4a are consistent with existing studies for a few other cities, such as Bucharest (Tumanov et al. 1999), Paris (Lemonsu and Masson 2002), New York City (Gedzelman et al. 2003), Orlando (Yow and Carbone 2006), London (Bohnenstengel et al. 2011; Chemel and Sokhi 2012; Barlow et al. 2015), Thessaloniki, and Athens (Giannaros and Melas 2012; Giannaros et al. 2013). In all of these studies, UHI intensity was quantified using near-surface air temperature. Reversed diurnal variation of UHII (i.e., higher UHII during daytime than nighttime) was reported when it was quantified using remotely sensed land surface temperature (Imhoff et al. 2010; Peng et al. 2012; Zhao et al. 2014). As discussed in the introduction, remotely sensed land surface temperatures and UHIIs must be carefully interpreted and do not necessarily characterize well urban temperatures. Another advantage of quantifying UHII using near-surface air temperature is that ambient air temperature is directly related to public health (Basara et al. 2010; Tan et al. 2010; Oswald et al. 2012). Future studies to further investigate the two different quantifications of UHII (i.e., using air temperature and land surface temperature) and combine their advantages are greatly needed (Schwarz et al. 2012). 


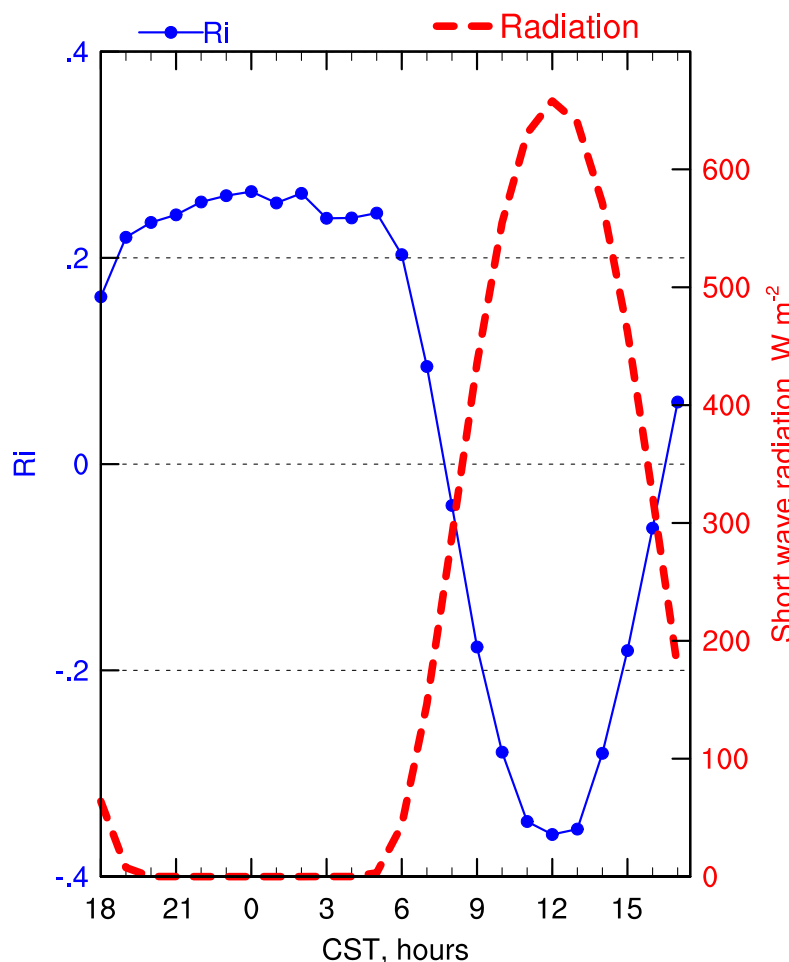

FIG. 5. Mean diurnal variation of Richardson number Ri and shortwave radiation at 10 Oklahoma Mesonet sites around OKC (i.e., OKCE, OKCN, OKCW, MINC, SPEN, ELRE, GUTH, KIN2, NRMN, and WASH) during April 2009-October 2010.

The rapid increase of UHII around the EET is likely related to rapid changes of mean flow and turbulence in the ABL. Around sunset, with the rapid decline of solar radiation and sustained radiational cooling of the surface, upward sensible heat fluxes decreased and convective eddies subsided quickly. Consequently, near-surface atmospheric stability increased quickly as indicated by the rapid increase of mean $\mathrm{Ri}$ at the Oklahoma Mesonet sites around OKC (Fig. 5). At 1900 CST, the mean Ri became larger than 0.2 , which is considered a quite stable condition (Banta et al. 2003; Galperin et al. 2007). Turbulent kinetic energy (TKE) in the upper part of the ABL decays quickly during the EET, and this part of the ABL becomes the residual layer, which often becomes decoupled from the newly formed stable layer near the surface (Acevedo and Fitzjarrald 2001; Acevedo et al. 2012; Bonin et al. 2013; Rizza et al. 2013; Klein et al. 2014). Rapid reduction of near-surface wind speed around 1800 CST (Fig. 6) is an indication of decoupling of the near-surface stable boundary layer from the upper layers with larger horizontal momentum. Impacts of surface heterogeneities (urban vs rural) are enhanced in the shallow, nearsurface, stable boundary layer (Godowitch et al. 1987;

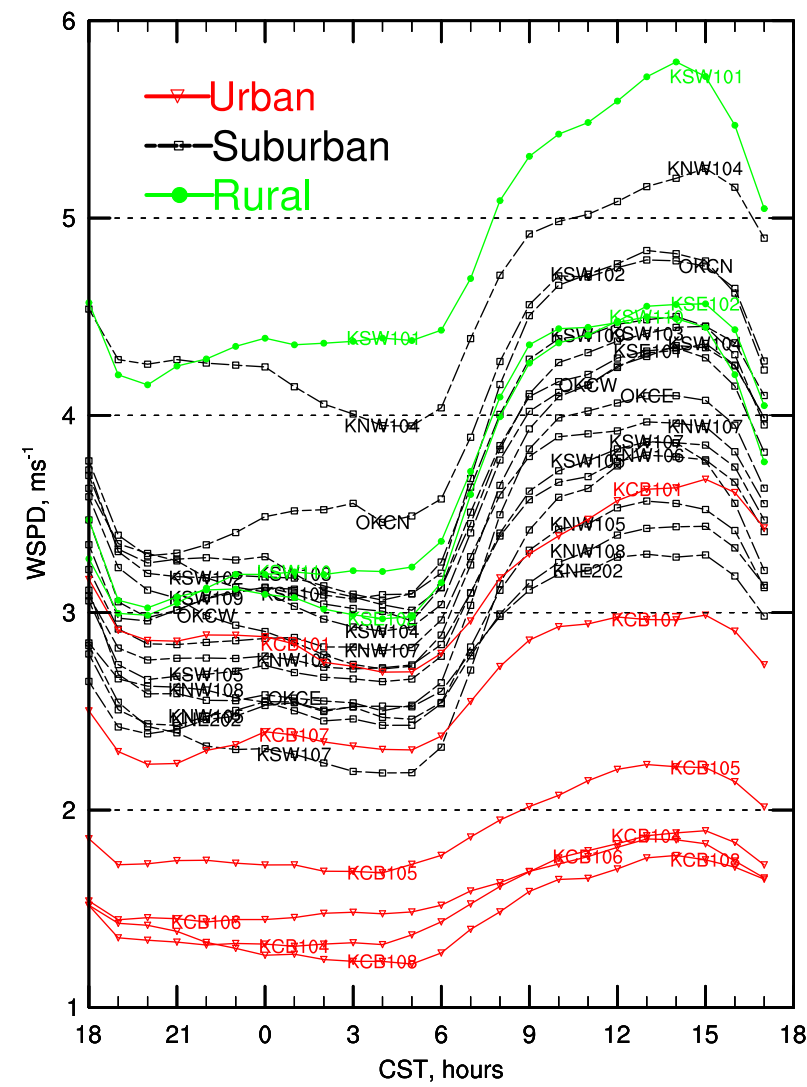

FIG. 6. Mean diurnal variation of wind speed (WSPD) at OKCNET sites during April 2009-October 2010.

Acevedo and Fitzjarrald 2001). Rural, near-surface temperature drops quickly in the shallow, stable boundary layer due to radiational cooling of the surface. In contrast, the longwave radiative heat loss at street level in urban areas is reduced due to multiple reflections among urban buildings (Oke 1981). Meanwhile, heat stored in the urban materials during the day begins to release during the EET (Ogoli 2003; Harman and Belcher 2006; Liu et al. 2006; Zhu et al. 2009; Bohnenstengel et al. 2011; Zajic et al. 2011; Yang et al. 2013). Together with anthropogenic heat, this extra heat in the urban region is released into and confined in the urban boundary layer (Ichinose et al. 1999; Fan and Sailor 2005; Grossman-Clarke et al. 2005; Rizwan et al. 2008; Schlünzen et al. 2010; Kotthaus and Grimmond 2014a,b; Barlow et al. 2015). Consequently, urban nearsurface temperatures decrease slowly in a more neutral urban boundary layer induced by the stronger turbulent vertical mixing due to higher heat emissions and rougher surface in cities (Clarke 1969; Oke 1987; Uno et al. 1988; Martilli et al. 2002; Nelson et al. 2011; Salamanca et al. 2014; Bohnenstengel et al. 2015). As a result of different cooling rates at rural and urban sites for $2-3 \mathrm{~h}$, UHII 


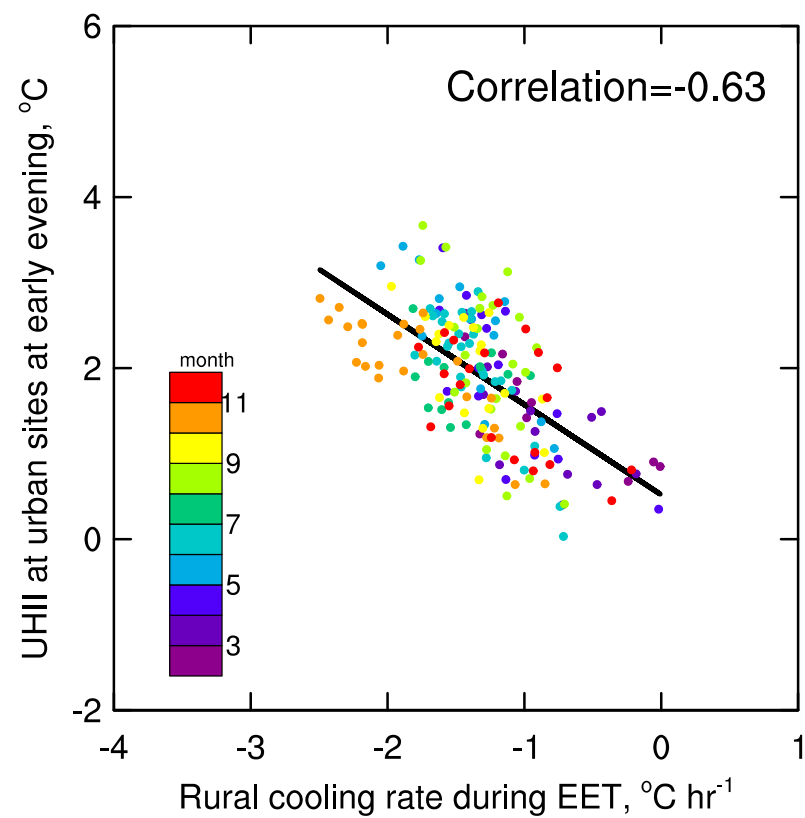

FIG. 7. Correlation between rural cooling rate during the EET (i.e., $2 \mathrm{~h}$ before sunset) and average UHII at early evening ( $2 \mathrm{~h}$ after sunset) at OKCNET urban sites during April 2009-October 2010.

increased quickly during the EET and stayed at a roughly constant level for the rest of the night (Figs. 4a,b).

Previous studies suggested that the spatial variability of temperature in rural areas played a very important role in determining the UHII (Hawkins et al. 2004). A question arises as to how important the EET cooling rate in rural areas is for UHI development (Yow and Carbone 2006). The relationship between rural background temperature change rate during the EET ( $2 \mathrm{~h}$ before sunset) and that of UHI intensity immediately after the EET ( $2 \mathrm{~h}$ after sunset) are thus further examined (Fig. 7). The mean UHI intensity at the OKCNET "urban" sites (i.e., KCB101-109; Basara et al. 2010) is chosen for analysis. Different sunset times during different months are accounted for. The statistic investigation based on 2009/10 data demonstrates that the near-surface cooling rate in the rural area around OKC during the EET shows a significant correlation with the UHI intensity at early evening with a correlation coefficient of -0.63 (Fig. 7). The mean UHI intensity at early evening roughly represents the mean nighttime UHI intensity (Fig. 4a). Thus, the near-surface cooling rate in the rural area during the EET is confirmed to play a critical role in determining the nocturnal UHI intensity with strong (weak) EET cooling rate likely leading to strong (weak) nocturnal UHI.

Similar to the cooling rate during the EET, the heating rate during the morning transition was also larger in the rural than urban area (figure not shown), which is consistent with previous studies (Oke 1987). The average absolute values of temperature change rate during the early evening and morning transition are shown in Fig. 8 . The temperature change rate shows a concentric distribution with the lowest rate located over OKC's CBD and increases from urban to rural zones (Fig. 8), indicating the moderating effects of urban to diurnal temperature change. The temperature change rate during the evening and morning transition may provide an alternate way to estimate the magnitude of urban footprints.

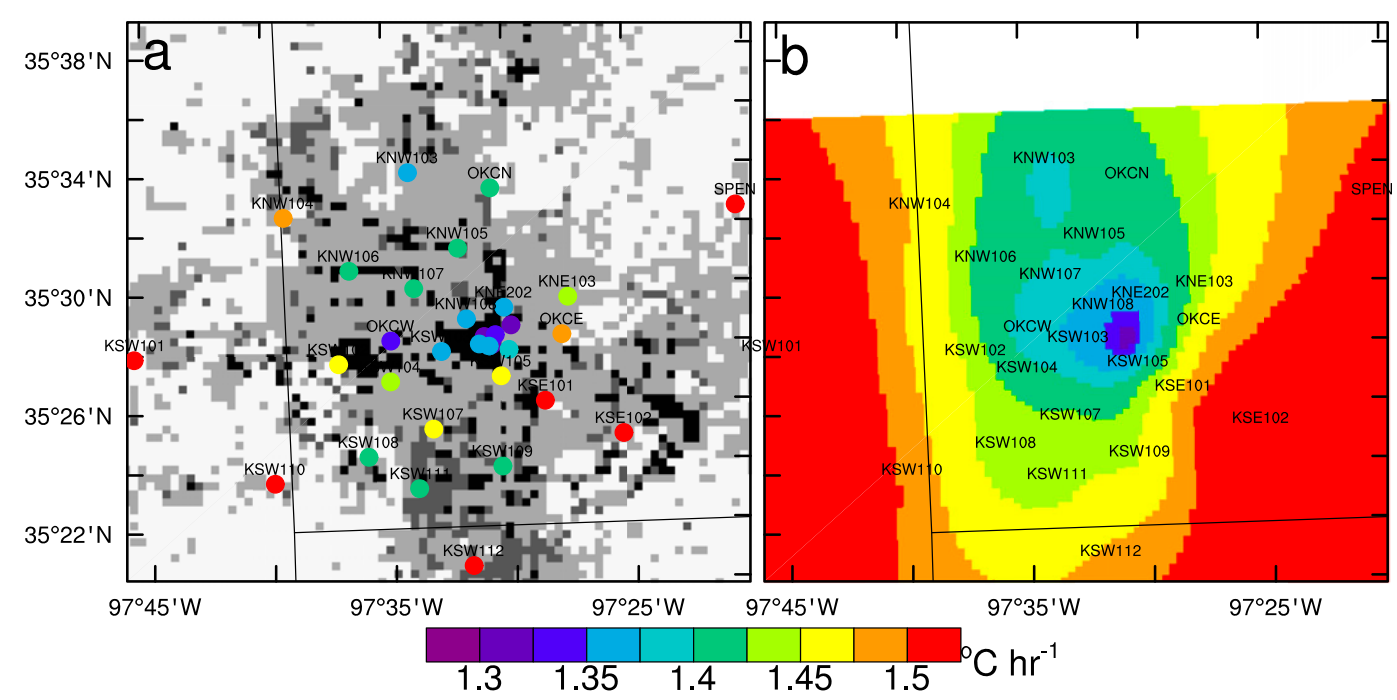

FIG. 8. Spatial distribution of average temperature change rate during the early evening and morning transition based on (a) spatially distributed observations and (b) kriging analysis. 
As discussed above, UHI intensity exhibited a large spatial variation over OKC (Figs. 2, 3, 4). UHI intensity over OKCNET sites varied between $0.4^{\circ}$ and $2.1^{\circ} \mathrm{C}$ during nighttime, while it varied between $-0.2^{\circ}$ and $1.0^{\circ} \mathrm{C}$ during the daytime (Fig. 4a). The large spatial variation of UHI intensity over OKC may be primarily caused by the different surface structures and cover at each site, as also reported for other cities (e.g., Shahgedanova et al. 1997; Eliasson and Svensson 2003; Alcoforado and Andrade 2006; Kolokotroni and Giridharan 2008; Bohnenstengel et al. 2011; Brandsma and Wolters 2012; Oswald et al. 2012; Suomi and Kayhko 2012; van Hove et al. 2015). Classifying all the sites in cities with different surface structure and cover into a single urban category may be inadequate to accurately quantify UHI in terms of its intensity and variation (Stewart 2011; Stewart and Oke 2012). According to the three-category (i.e., urban, suburban, and rural) classification of Basara et al. (2010), most of the sites starting with KCB (except KCB110) are located in the $\mathrm{CBD}$ and their surface type is classified as urban. These urban sites experienced higher UHI intensities than most of the remaining OKCNET sites during both daytime and nighttime (Figs. 2, 3, 4). Four OKCNET sites (i.e., KSW101, KSW110, KSE102, and KNE103) are classified as "rural" surface types in Basara et al. (2010), and these sites experienced lower UHI intensities than most of the other OKCNET sites (Figs. 2, $3,4)$. The large spatial variation of UHI intensity across OKC suggests that determining UHI intensity using the temperature difference between a certain urban site and a certain rural site may lack objective meaning and climatological relevance. These results thus justify the proposal by a few recent studies (e.g., Basara et al. 2010) of classifying measurement sites into detailed (to certain degrees) urban categories for objective UHI quantification and description.

The Basara et al. (2010) three-category classification is further compared with the more detailed classification of seven different UCZs defined by Oke (2004). The UHII diurnal variation shows a large variability within individual UCZs (Fig. 4b), while the three-category classification better captures the differences in the UHII characteristics among the OKCNET sites. We have thus decided to use the classification into rural, suburban, and urban sites as proposed by Basara et al. (2010) in this study.

\section{2) WIND SPEED AND IMPLICATIONS FOR TREATMENTS IN NUMERICAL MODELS}

Because of the diurnal variation of vertical coupling strength (strong coupling in daytime and weaker coupling at nighttime), the diurnal cycle of surface wind was

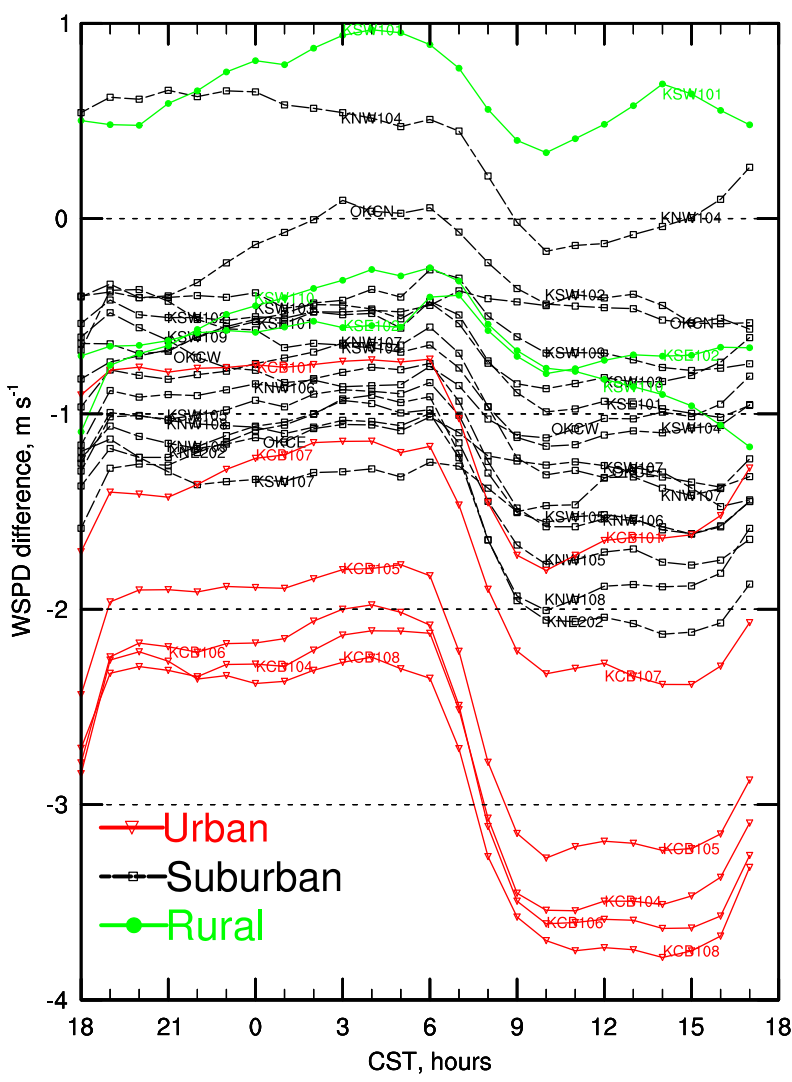

FIG. 9. Mean diurnal variation of wind speed difference between OKCNET sites and the seven surrounding Oklahoma Mesonet sites during April 2009-October 2010.

prominent, exhibiting a maximum (minimum) in the daytime (nighttime) (Fig. 6). During the daytime, stronger downward transport of boundary layer momentum led to stronger surface winds than are observed at night. Wind speeds at each individual site were largely determined by the roughness of each site (Kamal et al. 2015) and wind climatology in its surrounding environment. Two OKCNET sites on the west side of OKC, KNW104 (suburban) and KSW101 (rural) with relatively low roughness being located on dispersed settlement and grassland (Basara et al. 2011), experienced strong wind speeds (Figs. 2c,d, 9). The climatological east-to-west gradient of wind speed in the presence of dominant southerly wind in Oklahoma (Song et al. 2005) is another factor to explain the large wind speeds at these sites. Such an east-to-west gradient of southerly wind speed in Oklahoma was previously noticed in both observation and modeling results ( $\mathrm{Hu}$ et al. 2013a; $\mathrm{Hu}$ et al. 2013b).

Urbanization can have two different effects on surface wind: (i) enhanced surface roughness reduces surface wind speeds (Kamal et al. 2015), while (ii) stronger downward momentum transport due to enhanced 

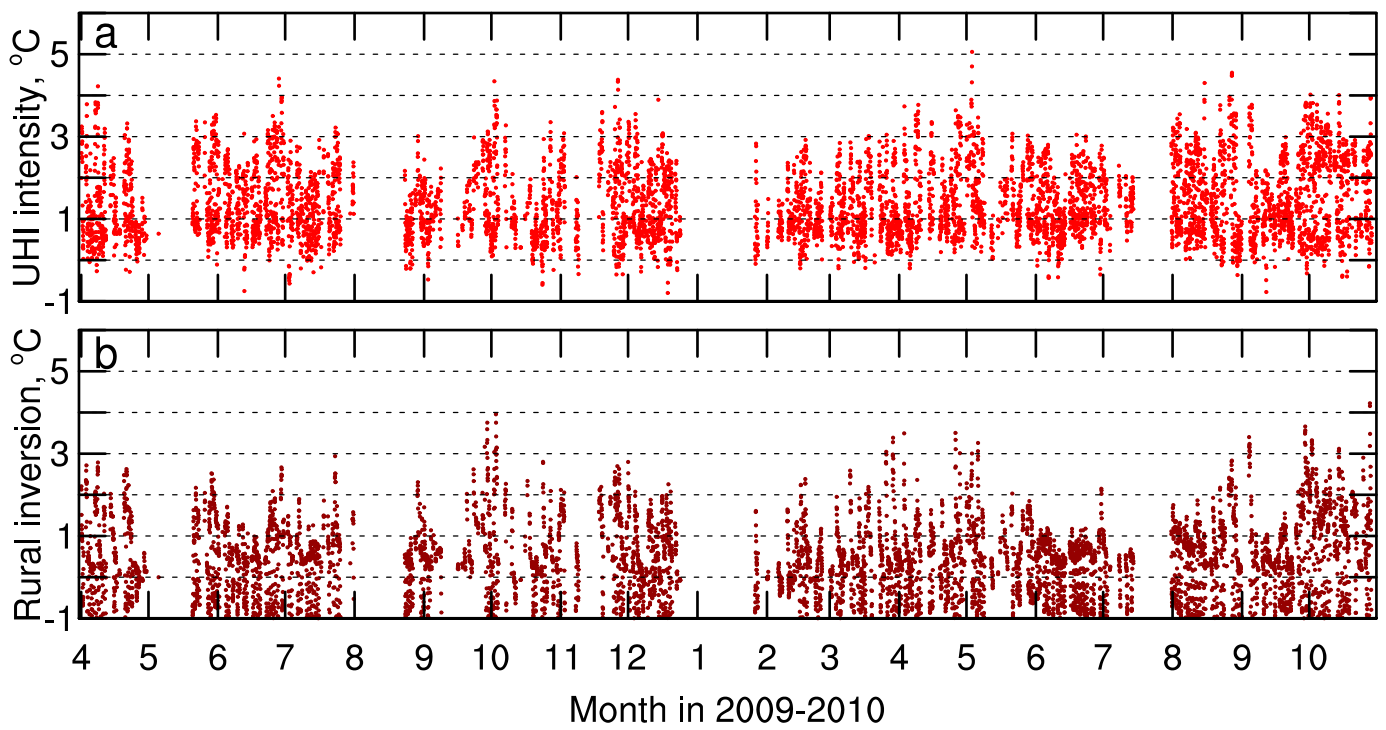

FIG. 10. Time series of (a) UHII at OKCNET urban sites and (b) rural average temperature inversion at the seven surrounding Oklahoma Mesonet sites during April 2009-October 2010.

vertical mixing increases surface speeds (Y. Wang et al. 2007; Hu et al. 2013b). Wind speeds at OKCNET sites (except KNW104 and KSW101) were always smaller than at the surrounding rural Oklahoma Mesonet sites (Fig. 9), which suggests that the effects of the enhanced urban surface roughness were dominant. The urban effect on wind in terms of the magnitude of wind speed reduction was more prominent during the daytime than during nighttime. The reductions of near-surface wind speed in the CBD area are as large as $3.5 \mathrm{~m} \mathrm{~s}^{-1}$ during daytime, whereas the magnitude of wind speed reduction decreases to $2 \mathrm{~m} \mathrm{~s}^{-1}$ during nighttime (Fig. 9).

Figures 2, 3, and 9 imply that the near-surface wind speed in urban areas is typically weaker than over the surrounding rural areas due to the dominant effects of enhanced roughness in urban areas. However, in threedimensional simulations with the Weather Research and Forecasting (WRF) Model, higher values of near-surface wind speed are at times simulated over urban than over rural areas (e.g., during the early evening transition; see Fig. A1 in the online supplemental material). These results, which are likely unrealistic according the wind speed data observed at the OKCNET sites, suggest that the vertical transport of momentum in mesoscale models may be overestimated. The advancement of model capability to handle vertical transport of momentum has been slower compared to the advancement of model capability to handle transport of scalars because most previous research efforts in terms of vertical transport had been focused on scalars rather than momentum (Frech and Mahrt 1995; Storm et al. 2009; Hu et al. 2013a; Ngan et al. 2013; Draxl et al. 2014; Gutiérrez et al. 2015).

\section{b. Seasonal variation of UHI}

Seasonal variation of UHI intensity in OKC during April 2009-October 2010 (Fig. 10a) did not show a clear warm-cold season contrast as reported in other cities (e.g., Magee et al. 1999; Steinecke 1999; Montávez et al. 2000; Jonsson 2004; Kim and Baik 2005; Hinkel and Nelson 2007; Zhou and Shepherd 2010; Memon et al. 2011; Yang et al. 2013). Hu et al. (2013b) concluded that rural temperature inversion strength can serve as an indicator of nocturnal UHI intensity based on the analysis of temperature data in July 2003 and model simulation results. Thus, temperature inversion strength (defined as the temperature difference between 1.5 and $9 \mathrm{~m} \mathrm{AGL}$ ) at the seven surrounding Oklahoma Mesonet sites is also examined (Fig. 10b). The temperature inversion strength had a similar variation as that of UHII and did not show a clear warm-cold season contrast. Monthly variation of percentiles (median, $25 \% / 75 \%$, and $5 \% / 95 \%$ ) of daily mean nocturnal UHII was also similar to those of nocturnal rural inversion strength (Fig. 11), even though the monthly percentiles may not be statistically significant in certain months due to many missing values because of precipitations (see Fig. 10). The UHII and surrounding rural inversion strength had a significant correlation during nighttime (2200-0500 CST) with a correlation coefficient of 0.79 (Fig. 12a). As discussed above, urban effects including reduced outgoing longwave radiation, extra heat, and stronger roughness lead to a more neutral and relatively thicker urban boundary layer and slower temperature decrease in contrast to rapid temperature decrease in the shallow 

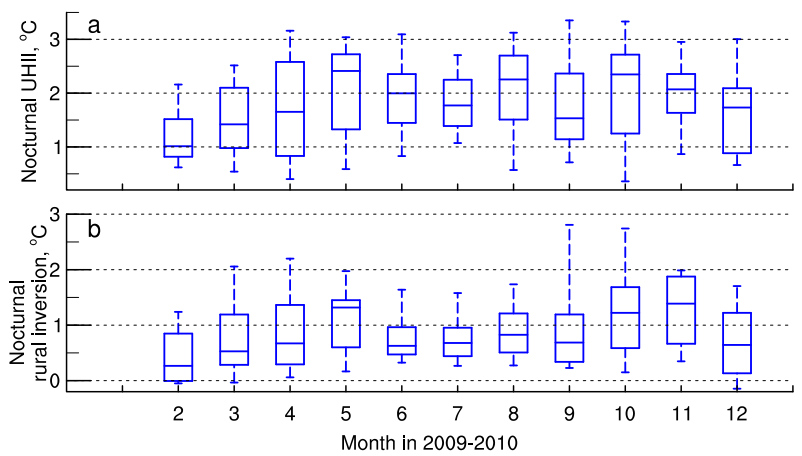

FIG. 11. Monthly variation of median, $25 \% / 75 \%$, and $5 \% / 95 \%$ percentiles of mean nocturnal (2200-0500 CST) (a) UHII and (b) rural inversion strength around OKC during April 2009October 2010.

stable rural boundary layer during the EET. Stronger rural temperature inversion is normally associated with a shallower and more stable boundary layer and allows urban effects to manifest more prominently with higher UHI intensity ( $\mathrm{Hu}$ et al. 2013b), effectively explaining the positive correlation between rural inversion strength and UHI intensity. Two exceptional points (i.e., 29 March 2010 and 29 October 2010) stand out in Fig. 12a. Two reasons were responsible for these exceptions: first, extremely strong inversion $\left(\sim 8^{\circ} \mathrm{C}\right.$ between 1.5 and $9 \mathrm{~m} \mathrm{AGL}$ ) occurred at the ELRE Oklahoma Mesonet site on these nights. Similar significant nocturnal inversion at the ELRE site in presence of clam winds, low humidity, and clear skies was previously noticed and reported by Hunt et al. (2007); second, nocturnal warming events occurred at the MINC Oklahoma Mesonet site. Various nocturnal warming events may occur at certain rural stations for a few reasons (White 2009; Nallapareddy et al. 2011; Hu et al. 2013c; Hu and Xue 2016), including cold front passages. Detailed investigation of the rural nocturnal warming events is beyond the scope of this study.

Given the significant correlation between rural inversion strength and nocturnal UHII, further investigation of a longer term of rural inversion strength can help diagnose the seasonal variation of nocturnal UHI intensity. Thus, longer-term Oklahoma Mesonet data (April 2009-December 2012) are examined. Monthly variation of median, $25 \% / 75 \%$, and $5 \% / 95 \%$ percentiles of daily mean nocturnal rural inversion strength around OKC during this longer period is shown in Fig. 13. The years 2011 and 2012 were exceptionally dry (Ramsey et al. 2014). There were only a few precipitation events during these years; thus, more inversion data are counted and the statistics are more reliable than those in Fig. 11b. The maximum median nocturnal inversion occurred in October. The standard deviations of rural inversion were smaller and the extreme values (indicated by $95 \%$ percentile) of rural inversion were lower in June and July (Fig. 13). Given the relationship between rural inversion and UHI intensity discussed above, the strongest nocturnal UHI was less likely to occur in June and July.

Wind speed has been reported to modulate UHI intensity in various cities (Morris et al. 2001; Unger et al. 2001; Fast et al. 2005; Steeneveld et al. 2011). The

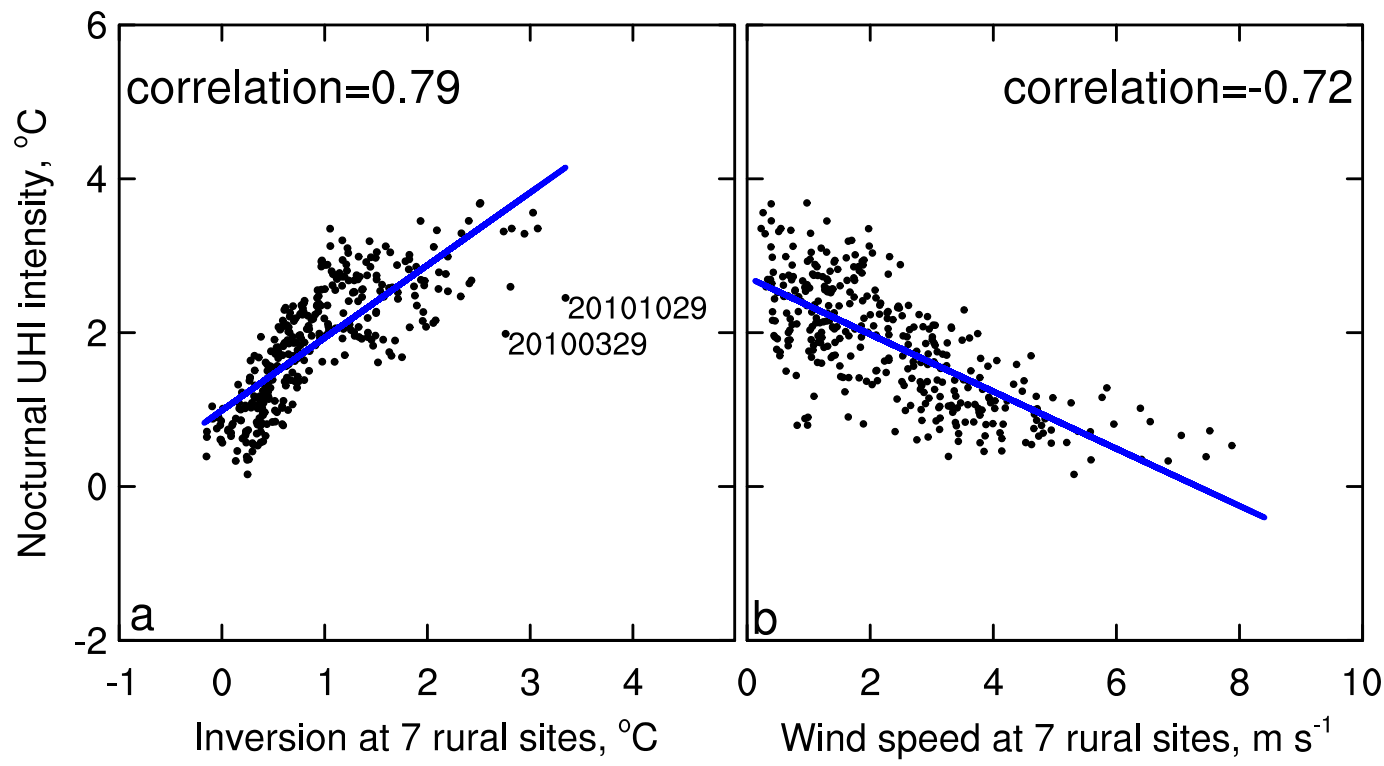

FIG. 12. Correlations between daily nocturnal (2200-0500 CST) UHII at the OKCNET urban sites and (a) rural inversion strength and (b) rural wind speed during April 2009-October 2010. 


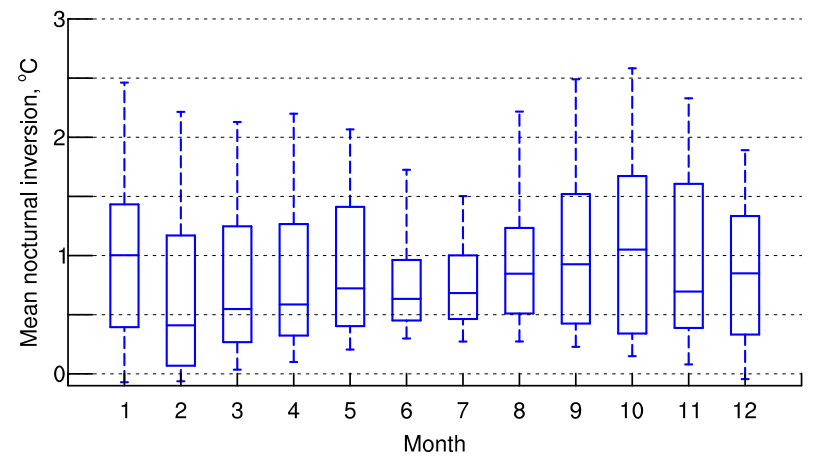

FIG. 13. Monthly variation of median, $25 \% / 75 \%$, and 5\%/95\% percentiles of mean nocturnal (2200-0500 CST) rural inversion strength around OKC during April 2009-December 2012.

correlation between rural wind speed and nocturnal UHI intensity during April 2009-October 2010 was examined. Nocturnal UHI intensity normally decreased with increased wind speed with a correlation coefficient of -0.72 (Fig. 12b). Larger wind speed leads to stronger turbulence and stronger mechanical vertical mixing, which reduce or eliminate rural background nocturnal temperature inversion. Since rural temperature inversion is a good indicator of nocturnal UHI intensity as discussed above, larger wind speeds decrease UHI intensity. Other processes (e.g., clouds) also play roles in modulating UHI intensity (Morris et al. 2001; Rosenzweig et al. 2005; Yow and Carbone 2006; Hoffmann et al. 2012), which can partially explain the scattering of the data points in Fig. 12b. Unfortunately, cloud data are not available from OKCNET and Oklahoma Mesonet sites.

Even though a clear warm-cold season contrast in the magnitude of UHII in OKC was not discerned during April 2009-October 2010 (Fig. 10a), seasonal variation of the timing of UHI was prominent (Fig. 14). Figure 14 shows the mean UHII at OKCNET sites as a function of month and time of the day. Note comparison of UHI intensity between different months in Fig. 14 is not meaningful since the number of available data during each month is different (see the data availability in Fig. 10a after removing the periods with precipitation and missing data at certain sites). Figure 14 further confirms the prominent diurnal variation of UHI intensity; that is, nocturnal UHI was strong, while daytime UHI was weak. The timing of onset/subsiding of nocturnal UHI showed a clear monthly variation. The time span of nocturnal UHI was short during warm months, while it was relatively longer during cold months. The onset timing of nocturnal UHI roughly followed the sunset time. This further confirms the critical roles played by the physical processes during the EET in the development of UHI.

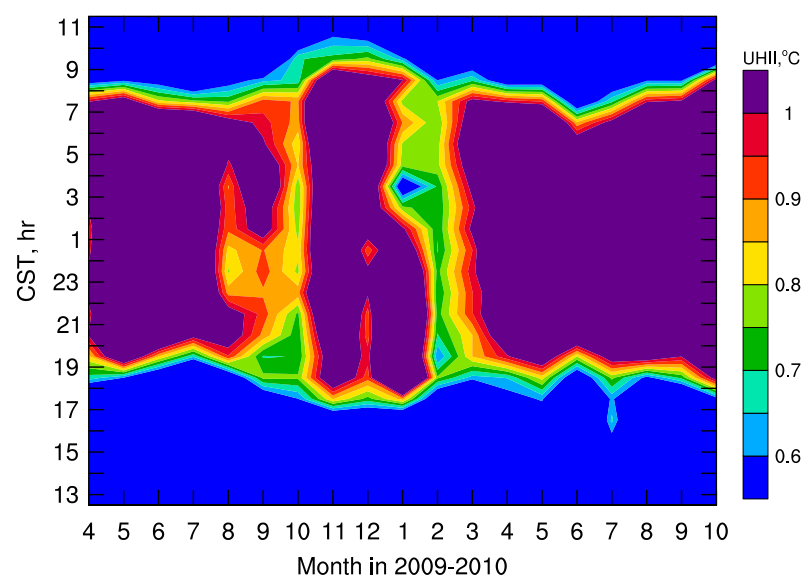

FIG. 14. Mean UHII over the OKCNET sites as a function of month and time of the day.

\section{Conclusions and discussion}

Using the data recorded from a dense surface observing network, that is, the Oklahoma City Micronet, during April 2009-October 2010, observed spatial distribution of UHII over Oklahoma City is investigated. UHII exhibited a large spatial variation over OKC. The widely varied UHII over OKC is partially explained by the different surface structure and cover at each site. The large variation of UHII across the urban area suggests that determining UHII using the temperature difference between an individual urban-rural site pair may lack objective meaning. It is better to classify measurement sites into detailed categories for objective UHI quantification and description as suggested by recent studies (e.g., Basara et al. 2010).

During both daytime and nighttime, the strongest UHII was mostly confined around the central business district where surface roughness is the highest in the OKC metropolitan area. These results do not corroborate the roughness warming theory of Zhao et al. (2014), according to which aerodynamically smoother urban areas would experience stronger daytime UHII than aerodynamically rougher urban areas (e.g., CBD).

UHII of OKC increased prominently around the early evening transition and stayed at a fairly constant level through the night. The boundary layer processes during the EET played a critical role in determining the nocturnal UHII in the absence of disturbances such as precipitation. Associated with the rapid decline of solar radiation during the EET, a stable boundary layer develops close to the ground. Rural temperatures in the shallow stable boundary layer decrease quickly due to radiative cooling. Meanwhile, heat stored in the urban building materials during the day released rapidly, together with the anthropogenic heat emissions, and 
heated the urban boundary layer. This extra heat, together with reduced outgoing longwave radiation (due to wall reflection, etc.) and elevated roughness, led to a more neutral urban boundary layer, in which temperature near the surface decreased slower than in the rural stable boundary layer. As a result of different cooling rates between urban and rural, UHII increased rapidly during the EET. The near-surface cooling rate in the rural area during the EET regulated the nocturnal UHII with a correlation coefficient of -0.63 . Factors such as wind speed and clouds may have affected the stability/ depth of the background nocturnal boundary layer, thus modulating UHII.

Nocturnal rural temperature inversion strength had a similar day-to-day variation as that of UHII. The nocturnal UHII and surrounding rural inversion strength are significantly correlated with a correlation coefficient of 0.79. A stronger rural inversion normally means a shallower surface layer and a larger EET temperature decrease in the rural area than in the urban area, which leads to a stronger UHII. The rural inversion strength did not show a clear warm season-cold season contrast during April 2009-October 2010. Thus, warm seasoncold season contrast of UHII in OKC was not prominent during this period. Analysis of a longer term (April 2009-December 2012) of rural inversion strength suggested that the strongest nocturnal UHI in OKC was more likely to occur in months other than June and July. Seasonal variation of the timing of UHI was prominent, with a shorter (longer) time span of nocturnal UHI during warm (cold) months, which is directly linked to the sunset and sunrise timings.

Though not shown here, surface ozone $\left(\mathrm{O}_{3}\right)$ was removed during the EET because of the deposition and chemical reactions in the stable boundary layer. A shallower stable boundary layer normally led to a quicker surface $\mathrm{O}_{3}$ reduction. The $\mathrm{O}_{3}$ removal rate during the EET showed a good correlation with the rural cooling rate. Thus, the characteristics of certain chemical species such as $\mathrm{O}_{3}$ during the EET can be used together with the rural cooling rates as indications of UHI development. The ambient concentration of other pollutants can be also indicative of the nocturnal UHII (Lai and Cheng 2009).

Acknowledgments. This work was supported by funding from the Office of the Vice President for Research at the University of Oklahoma. The second author was supported by NSF Grants AGS-0941491, AGS-1046171, AGS-1046081, and AGS-1261776. The third author started working with OKCNET data while being supported through the NSF Career Award ILREUM (NSF ATM 0547882) and now receives NSF support through Grant AGS-1359698. Three anonymous reviewers provided helpful comments that improved the manuscript.

\section{REFERENCES}

Acevedo, O. C., and D. R. Fitzjarrald, 2001: The early evening surface-layer transition: Temporal and spatial variability. J. Atmos. Sci., 58, 2650-2667, doi:10.1175/1520-0469(2001)058<2650: TEESLT $>2.0 . \mathrm{CO} ; 2$.

— F. D. Costa, and G. A. Degrazia, 2012: The coupling state of an idealized stable boundary layer. Bound.-Layer Meteor., 145, 211-228, doi:10.1007/s10546-011-9676-3.

Adachi, S. A., F. Kimura, H. Kusaka, M. G. Duda, Y. Yamagata, H. Seya, K. Nakamichi, and T. Aoyagi, 2014: Moderation of summertime heat island phenomena via modification of the urban form in the Tokyo metropolitan area. J. Appl. Meteor. Climatol., 53, 1886-1900, doi:10.1175/JAMC-D-13-0194.1.

Alcoforado, M. J., and H. Andrade, 2006: Nocturnal urban heat island in Lisbon (Portugal): Main features and modelling attempts. Theor. Appl. Climatol., 84, 151-159, doi:10.1007/ s00704-005-0152-1.

Alonso, M. S., M. R. Fidalgo, and J. L. Labajo, 2007: The urban heat island in Salamanca (Spain) and its relationship to meteorological parameters. Climate Res., 34, 39-46, doi:10.3354/ cr034039.

Arnfield, A. J., 2003: Two decades of urban climate research: A review of turbulence, exchanges of energy and water, and the urban heat island. Int. J. Climatol., 23, 1-26, doi:10.1002/ joc. 859 .

Banta, R. M., Y. L. Pichugina, and R. K. Newsom, 2003: Relationship between low-level jet properties and turbulence kinetic energy in the nocturnal stable boundary layer. J. Atmos. Sci., 60, 2549-2555, doi:10.1175/1520-0469(2003)060<2549: RBLJPA $>2.0 . \mathrm{CO} ; 2$.

Barlow, J. F., 2014: Progress in observing and modelling the urban boundary layer. Urban Climate, 10, 216-240, doi:10.1016/ j.uclim.2014.03.011.

, C. H. Halios, S. E. Lane, and C. R. Wood, 2015: Observations of urban boundary layer structure during a strong urban heat island event. Environ. Fluid Mech., 15, 373-398, doi:10.1007/ s10652-014-9335-6.

Basara, J. B., P. K. Hall, A. J. Schroeder, B. G. Illston, and K. L. Nemunaitis, 2008: Diurnal cycle of the Oklahoma City urban heat island. J. Geophys. Res., 113, D20109, doi:10.1029/ 2008JD010311.

, H. G. Basara, B. G. Illston, and K. C. Crawford, 2010: The impact of the urban heat island during an intense heat wave in Oklahoma City. Adv. Meteor., 2010, 230365, doi:10.1155/2010/ 230365 .

_ - and Coauthors, 2011: The Oklahoma City Micronet. Meteor. Appl., 18, 252-261, doi:10.1002/met.189.

Bodine, D., P. M. Klein, S. C. Arms, and A. Shapiro, 2009: Variability of surface air temperature over gently sloped terrain. J. Appl. Meteor. Climatol., 48, 1117-1141, doi:10.1175/ 2009JAMC1933.1.

Bohnenstengel, S. I., S. Evans, P. A. Clark, and S. E. Belcher, 2011: Simulations of the London urban heat island. Quart. J. Roy. Meteor. Soc., 137, 1625-1640, doi:10.1002/qj.855.

- and Coauthors, 2015: Meteorology, air quality, and health in London: The ClearfLo project. Bull. Amer. Meteor. Soc., 96, 779-804, doi:10.1175/BAMS-D-12-00245.1. 
Bonin, T., P. Chilson, B. Zielke, and E. Fedorovich, 2013: Observations of the early evening boundary-layer transition using a small unmanned aerial system. Bound.-Layer Meteor., 146, 119-132, doi:10.1007/s10546-012-9760-3.

Bottyán, Z., and J. Unger, 2003: A multiple linear statistical model for estimating the mean maximum urban heat island. Theor. Appl. Climatol., 75, 233-243, doi:10.1007/s00704-003-0735-7.

Brandsma, T., and D. Wolters, 2012: Measurement and statistical modeling of the urban heat island of the city of Utrecht (the Netherlands). J. Appl. Meteor. Climatol., 51, 1046-1060, doi:10.1175/JAMC-D-11-0206.1.

Brock, F. V., K. C. Crawford, R. L. Elliott, G. W. Cuperus, S. J. Stadler, H. L. Johnson, and M. D. Eilts, 1995: The Oklahoma Mesonet: A technical overview. J. Atmos. Oceanic Technol., 12, 5-19, doi:10.1175/1520-0426(1995)012<0005: TOMATO $>2.0 . \mathrm{CO} ; 2$.

Camilloni, I., and M. Barrucand, 2012: Temporal variability of the Buenos Aires, Argentina, urban heat island. Theor. Appl. Climatol., 107, 47-58, doi:10.1007/s00704-011-0459-z.

Chapman, L., C. L. Muller, D. T. Young, E. L. Warren, C. S. B. Grimmond, X.-M. Cai, and E. J. S. Ferranti, 2015: The Birmingham urban climate laboratory: An open meteorological test bed and challenges of the smart city. Bull. Amer. Meteor. Soc., 96, 1545-1560, doi:10.1175/BAMS-D-13-00193.1.

Chemel, C., and R. Sokhi, 2012: Response of London's urban heat island to a marine air intrusion in an easterly wind regime. Bound.-Layer Meteor., 144, 65-81, doi:10.1007/ s10546-012-9705-x.

Chen, F., and Coauthors, 2012: Research priorities in observing and modeling urban weather and climate. Bull. Amer. Meteor. Soc., 93, 1725-1728, doi:10.1175/BAMS-D-11-00217.1.

Chen, S., and Coauthors, 2014: Evaluation of high-resolution precipitation estimates from satellites during July 2012 Beijing flood event using dense rain gauge observations. PLoS One, 9 , e89681, doi:10.1371/journal.pone.0089681.

Chow, W. T. L., and M. Roth, 2006: Temporal dynamics of the urban heat island of Singapore. Int. J. Climatol., 26, 2243-2260, doi:10.1002/joc.1364.

Clarke, J. F., 1969: Nocturnal urban boundary layer over Cincinnati, Ohio. Mon. Wea. Rev., 97, 582-589, doi:10.1175/ 1520-0493(1969)097<0582:Nubloc $>2.3$.Co;2.

Clinton, N., and P. Gong, 2013: MODIS detected surface urban heat islands and sinks: Global locations and controls. Remote Sens. Environ., 134, 294-304, doi:10.1016/j.rse.2013.03.008.

Cui, Y. Y., and B. de Foy, 2012: Seasonal variations of the urban heat island at the surface and the near-surface and reductions due to urban vegetation in Mexico City. J. Appl. Meteor. Climatol., 51, 855-868, doi:10.1175/JAMC-D-11-0104.1.

Debbage, N., and J. M. Shepherd, 2015: The urban heat island effect and city contiguity. Comput. Environ. Urban Syst., 54 181-194, doi:10.1016/j.compenvurbsys.2015.08.002.

De Ridder, K., C. Bertrand, G. Casanova, and W. Lefebvre, 2012: Exploring a new method for the retrieval of urban thermophysical properties using thermal infrared remote sensing and deterministic modeling. J. Geophys. Res., 117, D17108, doi:10.1029/2011JD017194.

Dou, J. J., Y. C. Wang, R. Bornstein, and S. G. Miao, 2015: Observed spatial characteristics of Beijing urban climate impacts on summer thunderstorms. J. Appl. Meteor. Climatol., 54, 94 105, doi:10.1175/JAMC-D-13-0355.1.

Draxl, C., A. N. Hahmann, A. Pena, and G. Giebel, 2014: Evaluating winds and vertical wind shear from Weather Research and Forecasting Model forecasts using seven planetary boundary layer schemes. Wind Energy, 17, 39-55, doi:10.1002/ we. 1555

Eliasson, I., and M. K. Svensson, 2003: Spatial air temperature variations and urban land use-A statistical approach. Meteor. Appl., 10, 135-149, doi:10.1017/S1350482703002056.

Fan, H. L., and D. J. Sailor, 2005: Modeling the impacts of anthropogenic heating on the urban climate of Philadelphia: A comparison of implementations in two PBL schemes. Atmos. Environ., 39, 73-84, doi:10.1016/j.atmosenv.2004.09.031.

Fast, J. D., J. C. Torcolini, and R. Redman, 2005: Pseudovertical temperature profiles and the urban heat island measured by a temperature datalogger network in Phoenix, Arizona. J. Appl. Meteor., 44, 3-13, doi:10.1175/JAM-2176.1.

Fenner, D., F. Meier, D. Scherer, and A. Polze, 2014: Spatial and temporal air temperature variability in Berlin, Germany, during the years 2001-2010. Urban Climate, 10, 308-331, doi:10.1016/j.uclim.2014.02.004

Fortuniak, K., K. Kłysik, and J. Wibig, 2006: Urban-rural contrasts of meteorological parameters in Łódź. Theor. Appl. Climatol., 84, 91-101, doi:10.1007/s00704-005-0147-y.

Frech, M., and L. Mahrt, 1995: A two-scale mixing formulation for the atmospheric boundary layer. Bound.-Layer Meteor., 73, 91-104, doi:10.1007/BF00708931.

Fung, W. Y., K. S. Lam, J. Nichol, and M. S. Wong, 2009: Derivation of nighttime urban air temperatures using a satellite thermal image. J. Appl. Meteor. Climatol., 48, 863-872, doi:10.1175/2008JAMC2001.1.

Galperin, B., S. Sukoriansky, and P. S. Anderson, 2007: On the critical Richardson number in stably stratified turbulence. Atmos. Sci. Lett., 8, 65-69, doi:10.1002/asl.153.

Gedzelman, S. D., S. Austin, R. Cermak, N. Stefano, S. Partridge, S. Quesenberry, and D. A. Robinson, 2003: Mesoscale aspects of the urban heat island around New York City. Theor. Appl. Climatol., 75, 29-42, doi:10.1007/s00704-002-0724-2.

Georgakis, C., M. Santamouris, and G. Kaisarlis, 2010: The vertical stratification of air temperature in the center of Athens. J. Appl. Meteor. Climatol., 49, 1219-1232, doi:10.1175/2010JAMC2290.1.

Giannaros, T. M., and D. Melas, 2012: Study of the urban heat island in a coastal Mediterranean City: The case study of Thessaloniki, Greece. Atmos. Res., 118, 103-120, doi:10.1016/ j.atmosres.2012.06.006

, — — I. A. Daglis, I. Keramitsoglou, and K. Kourtidis, 2013: Numerical study of the urban heat island over Athens (Greece) with the WRF Model. Atmos. Environ., 73, 103-111, doi:10.1016/j.atmosenv.2013.02.055.

Godowitch, J. M., J. K. S. Ching, and J. F. Clarke, 1987: Spatial variation of the evolution and structure of the urban boundarylayer. Bound.-Layer Meteor., 38, 249-272, doi:10.1007/ BF00122447.

Grimmond, C. S. B., 2006: Progress in measuring and observing the urban atmosphere. Theor. Appl. Climatol., 84, 3-22, doi:10.1007/s00704-005-0140-5.

2007: Urbanization and global environmental change: Local effects of urban warming. Geogr. J., 173, 83-88, doi:10.1111/ j.1475-4959.2007.232_3.x.

— , and T. R. Oke, 1999: Heat storage in urban areas: Local-scale observations and evaluation of a simple model. J. Appl. Meteor., 38, 922-940, doi:10.1175/1520-0450(1999)038<0922: HSIUAL $>2.0 . \mathrm{CO} ; 2$.

and Coauthors, 2010: Climate and more sustainable cities: Climate information for improved planning and management of cities (producers/capabilities perspective). Procedia Environ. Sci., 1, 247-274, doi:10.1016/j.proenv.2010.09.016. 
Grossman-Clarke, S., J. A. Zehnder, W. L. Stefanov, Y. B. Liu, and M. A. Zoldak, 2005: Urban modifications in a mesoscale meteorological model and the effects on near-surface variables in an arid metropolitan region. J. Appl. Meteor., 44, 1281-1297, doi:10.1175/JAM2286.1.

Gutiérrez, E., A. Martilli, J. L. Santiago, and J. E. González, 2015: A mechanical drag coefficient formulation and urban canopy parameter assimilation technique for complex urban environments. Bound.-Layer Meteor., 157, 333-341, doi:10.1007/ s10546-015-0051-7.

Harman, I. N., and S. E. Belcher, 2006: The surface energy balance and boundary layer over urban street canyons. Quart. J. Roy. Meteor. Soc., 132, 2749-2768, doi:10.1256/qj.05.185.

Hart, M., and D. Sailor, 2009: Quantifying the influence of land-use and surface characteristics on spatial variability in the urban heat island. Theor. Appl. Climatol., 95, 397-406, doi:10.1007/ s00704-008-0017-5.

Hawkins, T. W., A. J. Brazel, W. L. Stefanov, W. Bigler, and E. M. Saffell, 2004: The role of rural variability in urban heat island determination for Phoenix, Arizona. J. Appl. Meteor., 43, 476486, doi:10.1175/1520-0450(2004)043<0476:TRORVI >2.0.CO;2.

Heusinkveld, B. G., G. J. Steeneveld, L. W. A. van Hove, C. M. J. Jacobs, and A. A. M. Holtslag, 2014: Spatial variability of the Rotterdam urban heat island as influenced by urban land use. J. Geophys. Res. Atmos., 119, 677-692, doi:10.1002/ 2012JD019399.

Hidalgo, J., V. Masson, and L. Gimeno, 2010: Scaling the daytime urban heat island and urban-breeze circulation. J. Appl. Meteor. Climatol., 49, 889-901, doi:10.1175/2009JAMC2195.1.

Hinkel, K. M., and F. E. Nelson, 2007: Anthropogenic heat island at Barrow, Alaska, during winter: 2001-2005. J. Geophys. Res., 112, D06118, doi:10.1029/2006JD007837.

Hoffmann, P., O. Krueger, and K. H. Schlunzen, 2012: A statistical model for the urban heat island and its application to a climate change scenario. Int. J. Climatol., 32, 1238-1248, doi:10.1002/ joc. 2348.

Hu, X.-M., and M. Xue, 2016: Influence of synoptic sea breeze fronts on the urban heat island intensity in Dallas-Fort Worth, Texas. Mon. Wea. Rev., doi:10.1175/MWR-D-15-0201.1, in press.

, P. M. Klein, and M. Xue, 2013a: Evaluation of the updated YSU planetary boundary layer scheme within WRF for wind resource and air quality assessments. J. Geophys. Res. Atmos., 118, 10 490-10 505, doi:10.1002/jgrd.50823.

,,,--- J. K. Lundquist, F. Q. Zhang, and Y. C. Qi, 2013b: Impact of low-level jets on the nocturnal urban heat island intensity in Oklahoma City. J. Appl. Meteor. Climatol., 52, 1779-1802, doi:10.1175/JAMC-D-12-0256.1.

,,--- A. Shapiro, and A. Nallapareddy, 2013c: Enhanced vertical mixing associated with a nocturnal cold front passage and its impact on near-surface temperature and ozone concentration. J. Geophys. Res. Atmos., 118, 2714-2728, doi:10.1002/jgrd.50309.

Huang, L. M., H. T. Li, D. H. Zha, and J. Y. Zhu, 2008: A fieldwork study on the diurnal changes of urban microclimate in four types of ground cover and urban heat island of Nanjing, China. Build. Environ., 43, 7-17, doi:10.1016/j.buildenv.2006.11.025.

Hunt, E. D., J. B. Basara, and C. R. Morgan, 2007: Significant inversions and rapid in situ cooling at a well-sited Oklahoma Mesonet station. J. Appl. Meteor. Climatol., 46, 353-367, doi:10.1175/JAM2467.1.

Husain, S. Z., S. Belair, J. Mailhot, and S. Leroyer, 2013: Improving the representation of the nocturnal near-neutral surface layer in the urban environment with a mesoscale atmospheric model. Bound.-Layer Meteor., 147, 525-551, doi:10.1007/ s10546-013-9798-x.

—, - and S. Leroyer, 2014: Influence of soil moisture on urban microclimate and surface-layer meteorology in Oklahoma City. J. Appl. Meteor. Climatol., 53, 83-98, doi:10.1175/ JAMC-D-13-0156.1.

Ichinose, T., K. Shimodozono, and K. Hanaki, 1999: Impact of anthropogenic heat on urban climate in Tokyo. Atmos. Environ., 33, 3897-3909, doi:10.1016/S1352-2310(99)00132-6.

Imhoff, M. L., P. Zhang, R. E. Wolfe, and L. Bounoua, 2010: Remote sensing of the urban heat island effect across biomes in the continental USA. Remote Sens. Environ., 114, 504-513, doi:10.1016/j.rse.2009.10.008.

Jin, M. S., 2012: Developing an index to measure urban heat island effect using satellite land skin temperature and land cover observations. J. Climate, 25, 6193-6201, doi:10.1175/ JCLI-D-11-00509.1.

Jonsson, P., 2004: Vegetation as an urban climate control in the subtropical city of Gaborone, Botswana. Int. J. Climatol., 24, 1307-1322, doi:10.1002/joc.1064.

Kamal, S., H.-P. Huang, and S. W. Myint, 2015: The influence of urbanization on the climate of Las Vegas metropolitan area: A numerical study. J. Appl. Meteor. Climatol., 54, 2157-2177, doi:10.1175/JAMC-D-15-0003.1.

Karl, T. R., H. F. Diaz, and G. Kukla, 1988: Urbanization: Its detection and effect in the United States climate record. J. Climate, 1, 1099-1123, doi:10.1175/1520-0442(1988)001<1099: UIDAEI $>2.0 . \mathrm{CO} ; 2$.

Kato, S., Y. Yamaguchi, C. C. Liu, and C. Y. Sun, 2008: Surface heat balance analysis of Tainan City on March 6, 2001 using ASTER and Formosat-2 data. Sensors, 8, 6026-6044, doi:10.3390/s8096026.

Kim, Y. H., and J. J. Baik, 2005: Spatial and temporal structure of the urban heat island in Seoul. J. Appl. Meteor., 44, 591-605, doi:10.1175/JAM2226.1.

Klein, P. M., 2012: Metropolitan effects on atmospheric patterns: Important scales. Metropolitan Sustainability: Understanding and Improving the Urban Environment, F. Zeman, Ed., Woodhead Publishing, 173-204.

_ , and J. Galvez, 2014: Flow and turbulence characteristics in a suburban street canyon. Environ. Fluid Mech., 15, 419-438, doi:10.1007/s10652-014-9352-5.

_ X. M. Hu, and M. Xue, 2014: Impacts of mixing processes in nocturnal atmospheric boundary layer on urban ozone concentrations. Bound.-Layer Meteor., 150, 107-130, doi:10.1007/ s10546-013-9864-4.

Klok, L., S. Zwart, H. Verhagen, and E. Mauri, 2012: The surface heat island of Rotterdam and its relationship with urban surface characteristics. Resour., Conserv. Recycl., 64, 23-29, doi:10.1016/j.resconrec.2012.01.009.

Klysik, K., and K. Fortuniak, 1999: Temporal and spatial characteristics of the urban heat island of Lodz, Poland. Atmos. Environ., 33, 3885-3895, doi:10.1016/S1352-2310(99)00131-4.

Kolokotroni, M., and R. Giridharan, 2008: Urban heat island intensity in London: An investigation of the impact of physical characteristics on changes in outdoor air temperature during summer. Sol. Energy, 82, 986-998, doi:10.1016/ j.solener.2008.05.004.

Kotthaus, S., and C. S. B. Grimmond, 2014a: Energy exchange in a dense urban environment-Part I: Temporal variability of long-term observations in central London. Urban Climate, $\mathbf{1 0}$, 261-280, doi:10.1016/j.uclim.2013.10.002. 
— ment-Part II: Impact of spatial heterogeneity of the surface. Urban Climate, 10, 281-307, doi:10.1016/j.uclim.2013.10.001.

Lai, L. W., and W. L. Cheng, 2009: Air quality influenced by urban heat island coupled with synoptic weather patterns. Sci. Total Environ., 407, 2724-2733, doi:10.1016/j.scitotenv.2008.12.002.

Lee, S. H., and J. J. Baik, 2010: Statistical and dynamical characteristics of the urban heat island intensity in Seoul. Theor. Appl. Climatol., 100, 227-237, doi:10.1007/s00704-009-0247-1.

Lee, X., and Coauthors, 2011: Observed increase in local cooling effect of deforestation at higher latitudes. Nature, 479, 384387, doi:10.1038/nature10588.

Lemonsu, A., and V. Masson, 2002: Simulation of a summer urban breeze over Paris. Bound.-Layer Meteor., 104, 463-490, doi:10.1023/A:1016509614936.

— , S. Belair, and J. Mailhot, 2009: The New Canadian Urban Modelling System: Evaluation for two cases from the Joint Urban 2003 Oklahoma City Experiment. Bound.-Layer Meteor., 133, 47-70, doi:10.1007/s10546-009-9414-2.

Li, D., E. Bou-Zeid, and M. Oppenheimer, 2014: The effectiveness of cool and green roofs as urban heat island mitigation strategies. Environ. Res. Lett., 9, 055002, doi:10.1088/1748-9326/9/ 5/055002.

Li, X. X., T. Y. Koh, D. Entekhabi, M. Roth, J. Panda, and L. K. Norford, 2013: A multi-resolution ensemble study of a tropical urban environment and its interactions with the background regional atmosphere. J. Geophys. Res. Atmos., 118, 9804-9818, doi:10.1002/jgrd.50795.

Li, Y. Y., H. Zhang, and W. Kainz, 2012: Monitoring patterns of urban heat islands of the fast-growing Shanghai metropolis, China: Using time-series of Landsat TM/ETM+ data. Int. J. Appl. Earth Obs. Geoinf., 19, 127-138, doi:10.1016/ j.jag.2012.05.001.

Liu, Y. B., F. Chen, T. Warner, and J. Basara, 2006: Verification of a mesoscale data-assimilation and forecasting system for the Oklahoma City area during the Joint Urban 2003 field project. J. Appl. Meteor. Climatol., 45, 912-929, doi:10.1175/ JAM2383.1.

Loughner, C. P., D. J. Allen, D. L. Zhang, K. E. Pickering, R. R. Dickerson, and L. Landry, 2012: Roles of urban tree canopy and buildings in urban heat island effects: Parameterization and preliminary results. J. Appl. Meteor. Climatol., 51, 17751793, doi:10.1175/JAMC-D-11-0228.1.

Magee, N., J. Curtis, and G. Wendler, 1999: The urban heat island effect at Fairbanks, Alaska. Theor. Appl. Climatol., 64, 39-47, doi:10.1007/s007040050109.

Martilli, A., A. Clappier, and M. W. Rotach, 2002: An urban surface exchange parameterisation for mesoscale models. Bound.-Layer Meteor., 104, 261-304, doi:10.1023/A:1016099921195.

McPherson, R. A., and Coauthors, 2007: Statewide monitoring of the mesoscale environment: A technical update on the Oklahoma Mesonet. J. Atmos. Oceanic Technol., 24, 301-321, doi:10.1175/JTECH1976.1.

Memon, R. A., D. Y. C. Leung, and C. H. Liu, 2009: An investigation of urban heat island intensity (UHII) as an indicator of urban heating. Atmos. Res., 94, 491-500, doi:10.1016/ j.atmosres.2009.07.006.

,,,--- and M. K. H. Leung, 2011: Urban heat island and its effect on the cooling and heating demands in urban and suburban areas of Hong Kong. Theor. Appl. Climatol., 103, 441-450, doi:10.1007/s00704-010-0310-y.

Meng, F., and M. Liu, 2013: Remote-sensing image-based analysis of the patterns of urban heat islands in rapidly urbanizing
Jinan, China. Int. J. Remote Sens., 34, 8838-8853, doi:10.1080/ 01431161.2013.853895.

Miao, S. G., F. Chen, M. A. Lemone, M. Tewari, Q. C. Li, and Y. C. Wang, 2009: An observational and modeling study of characteristics of urban heat island and boundary layer structures in Beijing. J. Appl. Meteor. Climatol., 48, 484-501, doi:10.1175/ 2008JAMC1909.1.

Mohsin, T., and W. A. Gough, 2012: Characterization and estimation of urban heat island at Toronto: Impact of the choice of rural sites. Theor. Appl. Climatol., 108, 105-117, doi:10.1007/ s00704-011-0516-7.

Montávez, J. P., A. Rodriguez, and J. I. Jimenez, 2000: A study of the urban heat island of Granada. Int. J. Climatol., 20, 899-911, doi:10.1002/1097-0088(20000630)20:8<899:: AID-JOC433>3.0.CO;2-I

Moriwaki, R., and M. Kanda, 2006: Scalar roughness parameters for a suburban area. J. Meteor. Soc. Japan, 84, 1063-1071, doi:10.2151/jmsj.84.1063.

Morris, C. J. G., and I. Simmonds, 2000: Associations between varying magnitudes of the urban heat island and the synoptic climatology in Melbourne, Australia. Int. J. Climatol., 20, 1931-1954, doi:10.1002/1097-0088(200012)20: 15<1931::AID-JOC578>3.0.CO;2-D.

- - - and N. Plummer, 2001: Quantification of the influences of wind and cloud on the nocturnal urban heat island of a large city. J. Appl. Meteor., 40, 169-182, doi:10.1175/1520-0450(2001)040<0169:QOTIOW >2.0.CO;2.

Muller, C. L., L. Chapman, C. S. B. Grimmond, D. T. Young, and X. M. Cai, 2013: Sensors and the city: A review of urban meteorological networks. Int. J. Climatol., 33, 1585-1600, doi:10.1002/joc.3678.

Nallapareddy, A., A. Shapiro, and J. J. Gourley, 2011: A climatology of nocturnal warming events associated with coldfrontal passages in Oklahoma. J. Appl. Meteor. Climatol., 50, 2042-2061, doi:10.1175/JAMC-D-11-020.1.

Nelson, M. A., E. R. Pardyjak, and P. Klein, 2011: Momentum and turbulent kinetic energy budgets within the Park Avenue Street canyon during the Joint Urban 2003 field campaign. Bound.-Layer Meteor., 140, 143-162, doi:10.1007/ s10546-011-9610-8.

Ngan, F., H. Kim, P. Lee, K. Al-Wali, and B. Dornblaser, 2013: A study of nocturnal surface wind speed overprediction by the WRF-ARW model in southeastern Texas. J. Appl. Meteor. Climatol., 52, 2638-2653, doi:10.1175/JAMC-D-13-060.1.

Nichol, J. E., W. Y. Fung, K. S. Lam, and M. S. Wong, 2009: Urban heat island diagnosis using ASTER satellite images and in situ' air temperature. Atmos. Res., 94, 276-284, doi:10.1016/ j.atmosres.2009.06.011.

Ogoli, D. M., 2003: Predicting indoor temperatures in closed buildings with high thermal mass. Energy Build., 35, 851-862, doi:10.1016/S0378-7788(02)00246-3.

Oke, T. R., 1976: The distinction between canopy and boundarylayer urban heat islands. Atmosphere, 14, 268-277, doi:10.1080/ 00046973.1976 .9648422$.

1981: Canyon geometry and the nocturnal urban heat-island: Comparison of scale model and field observations. Int. J. Climatol., 1, 237-254, doi:10.1002/joc.3370010304.

1982: The energetic basis of the urban heat-island. Quart. J. Roy. Meteor. Soc., 108, 1-24, doi:10.1002/qj.49710845502. 1987: Boundary Layer Climates. 2nd ed. Methuen, 435 pp. 2004: Initial guidance to obtain representative meteorological observations at urban sites. WMO Instruments and Observing Methods Rep. 81, WMO/TD 1250, 47 pp. 
G. T. Johnson, D. G. Steyn, and I. D. Watson, 1991: Simulation of surface urban heat islands under ideal conditions at night part 2: Diagnosis of causation. Bound.-Layer Meteor., 56, 339-358, doi:10.1007/BF00119211.

Oswald, E. M., R. B. Rood, K. Zhang, C. J. Gronlund, M. S. O’Neill, J. L. White-Newsome, S. J. Brines, and D. G. Brown, 2012: An investigation into the spatial variability of nearsurface air temperatures in the Detroit, Michigan, metropolitan region. J. Appl. Meteor. Climatol., 51, 1290-1304, doi:10.1175/JAMC-D-11-0127.1.

Peng, S. S., and Coauthors, 2012: Surface urban heat island across 419 global big cities. Environ. Sci. Technol., 46, 696-703, doi:10.1021/es2030438.

Philandras, C. M., D. A. Metaxas, and P. T. Nastos, 1999: Climate variability and urbanization in Athens. Theor. Appl. Climatol., 63, 65-72, doi:10.1007/s007040050092.

Ramsey, N. R., P. M. Klein, and B. Moore, 2014: The impact of meteorological parameters on urban air quality. Atmos. Environ., 86, 58-67, doi:10.1016/j.atmosenv.2013.12.006.

Rizwan, A. M., Y. C. L. Dennis, and C. H. Liu, 2008: A review on the generation, determination and mitigation of urban heat island. J. Environ. Sci., 20, 120-128, doi:10.1016/ S1001-0742(08)60019-4.

Rizza, U., M. M. Miglietta, G. A. Degrazia, O. C. Acevedo, and E. P. Marques, 2013: Sunset decay of the convective turbulence with large-eddy simulation under realistic conditions. Physica A, 392, 4481-4490, doi:10.1016/j.physa.2013.05.009.

Rosenzweig, C., W. D. Solecki, L. Parshall, M. Chopping, G. Pope, and R. Goldberg, 2005: Characterizing the urban heat island in current and future climates in New Jersey. Global Environ. Change, 6B, 51-62, doi:10.1016/j.hazards.2004.12.001.

Roth, M., T. R. Oke, and W. J. Emery, 1989: Satellite-derived urban heat islands from three coastal cities and the utilization of such data in urban climatology. Int. J. Remote Sens., 10, 16991720, doi:10.1080/01431168908904002.

Ryu, Y. H., and J. J. Baik, 2012: Quantitative analysis of factors contributing to urban heat island intensity. J. Appl. Meteor. Climatol., 51, 842-854, doi:10.1175/JAMC-D-11-098.1.

Sakakibara, Y., and K. Owa, 2005: Urban-rural temperature differences in coastal cities: Influence of rural sites. Int. J. Climatol., 25, 811-820, doi:10.1002/joc.1180.

Salamanca, F., M. Georgescu, A. Mahalov, M. Moustaoui, and M. Wang, 2014: Anthropogenic heating of the urban environment due to air conditioning. J. Geophys. Res. Atmos., 119, 5949-5965, doi:10.1002/2013JD021225.

Schatz, J., and C. J. Kucharik, 2014: Seasonality of the urban heat island effect in Madison, Wisconsin. J. Appl. Meteor. Climatol., 53, 2371-2386, doi:10.1175/JAMC-D-14-0107.1.

Schlünzen, K. H., P. Hoffmann, G. Rosenhagen, and W. Riecke, 2010: Long-term changes and regional differences in temperature and precipitation in the metropolitan area of Hamburg. Int. J. Climatol., 30, 1121-1136, doi:10.1002/joc.1968.

Schmidlin, T. W., 1989: The urban heat-island at Toledo, Ohio. Ohio J. Sci., 89, 38-41.

Schwarz, N., S. Lautenbach, and R. Seppelt, 2011: Exploring indicators for quantifying surface urban heat islands of European cities with MODIS land surface temperatures. Remote Sens. Environ., 115, 3175-3186, doi:10.1016/j.rse.2011.07.003.

— , U. Schlink, U. Franck, and K. Grossmann, 2012: Relationship of land surface and air temperatures and its implications for quantifying urban heat island indicators-An application for the city of Leipzig (Germany). Ecol. Indic., 18, 693-704, doi:10.1016/j.ecolind.2012.01.001.
Shahgedanova, M., T. P. Burt, and T. D. Davies, 1997: Some aspects of the three-dimensional heat island in Moscow. Int. J. Climatol., 17, 1451-1465, doi:10.1002/(SICI)1097-0088(19971115)17: 13<1451::AID-JOC201>3.0.CO;2-Z.

Smoliak, B. V., P. K. Snyder, T. E. Twine, P. M. Mykleby, and W. F. Hertel, 2015: Dense network observations of the Twin Cities canopy-layer urban heat island. J. Appl. Meteor. Climatol., 54, 1899-1917, doi:10.1175/JAMC-D-14-0239.1.

Song, J., K. Liao, R. L. Coulter, and B. M. Lesht, 2005: Climatology of the low-level jet at the southern Great Plains atmospheric boundary layer experiments site. J. Appl. Meteor., 44, 1593 1606, doi:10.1175/JAM2294.1.

Souch, C., and S. Grimmond, 2006: Applied climatology: Urban climate. Prog. Phys. Geogr., 30, 270-279, doi:10.1191/ 0309133306pp484pr.

Steeneveld, G. J., S. Koopmans, B. G. Heusinkveld, L. W. A. van Hove, and A. A. M. Holtslag, 2011: Quantifying urban heat island effects and human comfort for cities of variable size and urban morphology in the Netherlands. J. Geophys. Res., 116, D20129, doi:10.1029/2011JD015988.

Steinecke, K., 1999: Urban climatological studies in the Reykjavik subarctic environment, Iceland. Atmos. Environ., 33, 4157 4162, doi:10.1016/S1352-2310(99)00158-2.

Stewart, I. D., 2011: A systematic review and scientific critique of methodology in modern urban heat island literature. Int J. Climatol., 31, 200-217, doi:10.1002/joc.2141.

— perature studies. Bull. Amer. Meteor. Soc., 93, 1879-1900, doi:10.1175/BAMS-D-11-00019.1.

Stone, B., 2007: Urban and rural temperature trends in proximity to large US cities: 1951-2000. Int. J. Climatol., 27, 1801-1807, doi:10.1002/joc.1555.

Storm, B., J. Dudhia, S. Basu, A. Swift, and I. Giammanco, 2009: Evaluation of the Weather Research and Forecasting Model on forecasting low-level jets: Implications for wind energy. Wind Energy, 12, 81-90, doi:10.1002/we.288.

Sugawara, H., and K. Narita, 2009: Roughness length for heat over an urban canopy. Theor. Appl. Climatol., 95, 291-299, doi:10.1007/s00704-008-0007-7.

Suomi, J., and J. Kayhko, 2012: The impact of environmental factors on urban temperature variability in the coastal city of Turku, SW Finland. Int. J. Climatol., 32, 451-463, doi:10.1002/ joc. 2277.

Taha, H., 1997: Urban climates and heat islands: Albedo, evapotranspiration, and anthropogenic heat. Energy Build., 25, 99-103, doi:10.1016/S0378-7788(96)00999-1.

Tan, J. G., and Coauthors, 2010: The urban heat island and its impact on heat waves and human health in Shanghai. Int J. Biometeor., 54, 75-84, doi:10.1007/s00484-009-0256-x.

Theeuwes, N. E., A. Solcerova, and G. J. Steeneveld, 2013: Modeling the influence of open water surfaces on the summertime temperature and thermal comfort in the city. J. Geophys. Res. Atmos., 118, 8881-8896, doi:10.1002/jgrd.50704.

Tumanov, S., A. Stan-Sion, A. Lupu, C. Soci, and C. Oprea, 1999: Influences of the city of Bucharest on weather and climate parameters. Atmos. Environ., 33, 4173-4183, doi:10.1016/ S1352-2310(99)00160-0.

Unger, J., 2004: Intra-urban relationship between surface geometry and urban heat island: Review and new approach. Climate Res., 27, 253-264, doi:10.3354/cr027253.

- Z. Sumeghy, and J. Zoboki, 2001: Temperature cross-section features in an urban area. Atmos. Res., 58, 117-127, doi:10.1016/ S0169-8095(01)00087-4. 
Uno, I., S. Wakamatsu, H. Ueda, and A. Nakamura, 1988: An observational study of the structure of the nocturnal urban boundary-layer. Bound.-Layer Meteor., 45, 59-82, doi:10.1007/ BF00120815.

van Hove, L. W. A., C. M. J. Jacobs, B. G. Heusinkveld, J. A. Elbers, B. L. van Driel, and A. A. M. Holtslag, 2015: Temporal and spatial variability of urban heat island and thermal comfort within the Rotterdam agglomeration. Build. Environ., 83, 91-103, doi:10.1016/j.buildenv.2014.08.029.

Voogt, J. A., and T. R. Oke, 2003: Thermal remote sensing of urban climates. Remote Sens. Environ., 86, 370-384, doi:10.1016/ S0034-4257(03)00079-8.

Wang, K. C., J. K. Wang, P. C. Wang, M. Sparrow, J. Yang, and H. B. Chen, 2007: Influences of urbanization on surface characteristics as derived from the Moderate-Resolution Imaging Spectroradiometer: A case study for the Beijing metropolitan area. J. Geophys. Res., 112, D22S06, doi:10.1029/ 2006JD007997.

Wang, Y., C. L. Klipp, D. M. Garvey, D. A. Ligon, C. C. Williamson, S. S. Chang, R. K. Newsom, and R. Calhoun, 2007: Nocturnal low-level-jet-dominated atmospheric boundary layer observed by a Doppler lidar over Oklahoma City during JU2003. J. Appl. Meteor. Climatol., 46, 2098-2109, doi:10.1175/2006JAMC1283.1.

White, L. D., 2009: Sudden nocturnal warming events in Mississippi. J. Appl. Meteor. Climatol., 48, 758-775, doi:10.1175/ 2008JAMC1971.1.

Wienert, U., and W. Kuttler, 2005: The dependence of the urban heat island intensity on latitude-A statistical approach. $\mathrm{Me}$ teor. Z., 14, 677-686, doi:10.1127/0941-2948/2005/0069.

Winguth, A. M. E., and B. Kelp, 2013: The urban heat island of the north-central Texas region and its relation to the 2011 severe Texas drought. J. Appl. Meteor. Climatol., 52, 2418-2433, doi:10.1175/JAMC-D-12-0195.1.
Yang, P., G. Y. Ren, and W. D. Liu, 2013: Spatial and temporal characteristics of Beijing urban heat island intensity. J. Appl. Meteor. Climatol., 52, 1803-1816, doi:10.1175/ JAMC-D-12-0125.1.

Yow, D. M., and G. J. Carbone, 2006: The urban heat island and local temperature variations in Orlando, Florida. Southeast. Geogr., 46, 297-321, doi:10.1353/sgo.2006.0033.

Zajic, D., H. J. S. Fernando, R. Calhoun, M. Princevac, M. J. Brown, and E. R. Pardyjak, 2011: Flow and turbulence in an urban canyon. J. Appl. Meteor. Climatol., 50, 203-223, doi:10.1175/2010JAMC2525.1.

Zhang, J. H., Y. Y. Hou, G. C. Li, H. Yan, L. M. Yang, and F. M. Yao, 2005: The diurnal and seasonal characteristics of urban heat island variation in Beijing city and surrounding areas and impact factors based on remote sensing satellite data. Sci. China, 48D, 220-229, doi:10.1360/03ye0604

Zhang, P., M. L. Imhoff, R. E. Wolfe, and L. Bounoua, 2010: Characterizing urban heat islands of global settlements using MODIS and nighttime lights products. Can. J. Remote Sens., 36, 185-196, doi:10.5589/m10-039.

Zhao, L., X. Lee, R. B. Smith, and K. Oleson, 2014: Strong contributions of local background climate to urban heat islands. Nature, 511, 216-219, doi:10.1038/nature13462.

Zhou, Y., and J. M. Shepherd, 2010: Atlanta's urban heat island under extreme heat conditions and potential mitigation strategies. Nat. Hazards, 52, 639-668, doi:10.1007/s11069-009-9406-z.

Zhu, L., R. Hurt, D. Correia, and R. Boehm, 2009: Detailed energy saving performance analyses on thermal mass walls demonstrated in a zero energy house. Energy Build., 41, 303-310, doi:10.1016/j.enbuild.2008.10.003.

Zou, B., Y. Luo, N. Wan, Z. Zheng, T. Sternberg, and Y. Liao, 2015: Performance comparison of LUR and OK in $\mathrm{PM}_{2.5}$ concentration mapping: A multidimensional perspective. Sci. Rep., 5, 8698, doi:10.1038/srep08698. 